\title{
Strategies for Denaturing the Weapons-Grade Plutonium Stockpile (U)
}

M. R. Buckner

P. B. Parks

Contributors:

C. E. Ahlfeld M. R. Louthan, Jr.

C. E. Apperson I. M. Macafee

R. W. Benjamin F. J. McCrosson

J. T. Buckner, Jr. W. R. McDonell

$\begin{array}{ll}\text { R. L. Frost } & \text { D.F. Paddleford }\end{array}$

W. E. Graves H. B. Peacock

M. V. Gregory J. A. Radder

D. E. Hostetler R. W. Rathbun

N. C. Iyer

J. M. Stone

N. H. Kuehn $\quad$ M. C. Thompson

Westinghouse Savannah River Company Savannah River Site

Aiken, SC 29808

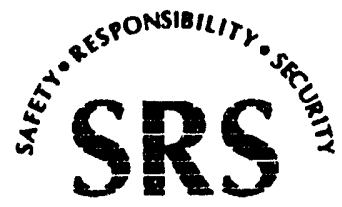

SAVANNAH RIVER SITE

Prepared for the U. S. Department of Energy under Contract No. DE-AC09-89SR18035 


\section{Approvals}

\section{Paul B. Panks}

P. B. Parks, Senior Fellow Scientist

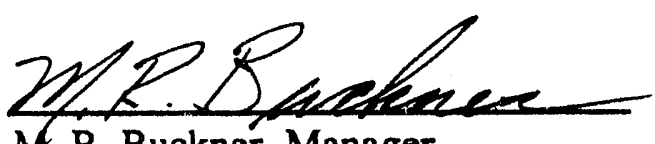

M. R. Buckner, Manager

Scientific Computations

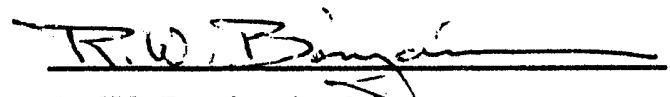

R. W. Benjamin, Mamager

Advanced Planning and Analysis

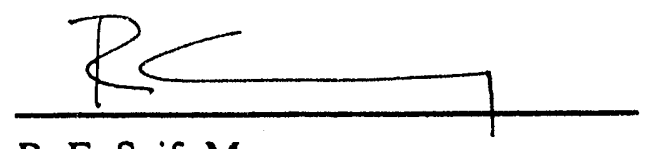

R. E. Seif, Manager

Transition and Reconfiguration

Program Integration

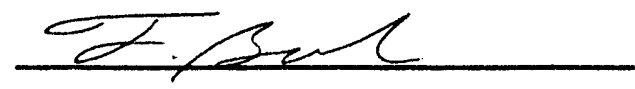

F. Beranek, Manager

Nuclear Reactor Technology and Scientific Computations
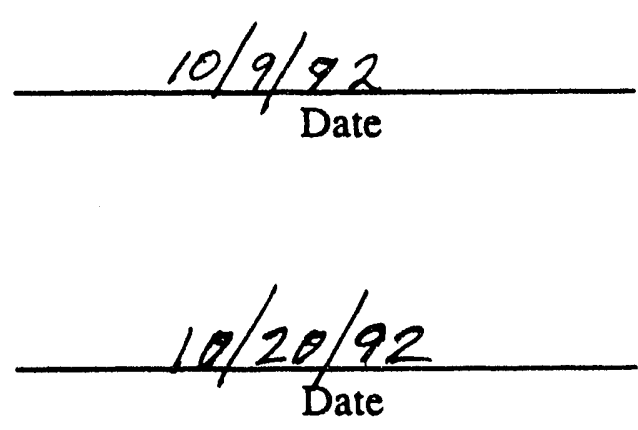

$10 / 9 / 92$

Date

$\frac{10 / 9 / 52}{\text { Date }}$

$10 / 20 / 92$

Date 


\section{Table of Contents}

Section

Page

Executive Summary

ES-1

1. Introduction

$1-1$

1.1 Purpose

$1-1$

1.2 Required Number of Plutonium-Fueled Reactors

$1-1$

1.3 Tritium Production Considerations

$1-1$

1.4 Regulatory Considerations

$1-1$

1.5 Reprocessing Considerations

$1-2$

1.6 Organization of the Report

$1-2$

2. Plutonium Fuel Experience

2.1 MOX Fuel in LWRs $2-1$

2.1.1 Historical Milestones 2-1

2.1.2 Current and Projected MOX Fuel Use 2-1

2.1.3 Characteristics of MOX Fuels 2-2

2.1.4 MOX Fuel Behavior 2-3

2.2 Plutonium Experience at SRS 2-4

3. Consumption of Plutonium in Reactors $3-1$

3.1 Initial LWR at SRS $3-1$

3.2 Utility LWRs 3-1

3.3 Multiple LWRs with Reprocessing and Actinide Burning 3-1

3.4 New Production Reactor 3-2

4. Strategy 1 - Utility Use of Plutonium Fuel 4-1

4.1 Phase 1 - Fuel Cycle Demonstration 4-1

4.1.1 MOX Fuel Plant at SRS 4-1

4.1.2 Initial LWR at SRS 4-5

4.1.3 Spent Fuel Management at SRS Without Reprocessing 4-6 
4.2 Phase 2 - Using MOX Fuel in Utility LWRs 4-8

4.2.1 Expanded MOX Fuel Plant 4-8

4.2.2 Utility LWR Use of Plutonium 4-8

4.2.3 Spent Fuel Management at Utilities 4-10

5. Strategy 2 - Energy Park Use of Plutonium Fuel 5-1

5.1 Initial LWR at SRS 5-1

5.2 Additional Reactors at SRS $5-1$

6. Summarized Costs for Plutonium Denaturing Strategies 6-1

6.1 Individual Components Costs $6-1$

6.2 Life Cycle Costs 6-1

$\begin{array}{lr}\text { 7. Recommendations } & 7-1\end{array}$

Appendix A. Tritium Target Technology $\quad$ A-1

A.1 Heavy Water-Production Reactor Target Technology A-1

A.2 High Temperature Target Development $\quad$ A-1

A.2.1 Aluminum Can Technology A-1

A.2.2 Getter-Barrier and Silicon-Carbide Technologies A-1

Appendix B. Burning Plutonium in Energy Park with Reprocessing and Actinide Burning

$\begin{array}{ll}\text { B.1 Fuel Fabrication } & \text { B-1 }\end{array}$

B.2 Reprocessing Plant B-2

B.3 Actinide Burning In Integral Fast Reactor B-6

B.4 Additional Reactors at SRS (with Reprocessing) B-7 
B.5 High-Level Waste Management at SRS with Reprocessing and Actinide Burning

B-7

B.5.1 Waste From LWR Fuel

B-7

B.5.2 Waste from Actinide Burning in Liquid Metal Reactors

B-8

Appendix C. Calculation of Co-Generation Electric Rate

C-1 


\section{List of Figures}

No. Title

Page

4.1 Comparison of the Reference and the New MOX Manufacturing Processes

4.2 Site Returns Processing 4-3

4.3 $\mathrm{UO}_{2}$ Conversion Process $\quad 4-4$

4.4 LWR Spent Fuel Management Without Reprocessing 4-8

4.5 Expanded MOX Facility to Supply Onsite Demonstration LWR and up to three Offsite Utility LWRs

B.1 SRS Fuel Cycle Using Injection Casting for IFR Fuel B-2

B.2 Flow Chart for IFR Fuel Fabrication B-3

B.3 Cross Section of the Alloy Preparation/Injection Casting Furnace B-4

$\begin{array}{lll}\text { B.4 Reprocessing Flow Diagram } & \text { B-5 }\end{array}$

B.5 Spent Fuel Reprocessing with Actinide Burning B-8

\section{List of Tables}

No. Title

Page

2.1 Comparison of Uranium and MOX Nuclear Design Characteristics

4.1 Comparison of Passive and Evolutionary Plant Output and Costs 4-7

6.1 DOE Costs and Revenue 6-2

6.2 Life Cycle Costs 6-3 


\section{Executive Summary}

In the next few years, approximately 50 metric tons of weapons-grade plutonium and 150 metric tons of highly-enriched uranium (HEU) may be removed from nuclear weapons in the U.S. and declared excess. These materials represent a significant energy resource that could substantially contribute to our national energy requirements. HEU can be used as fuel in naval reactors, or diluted with depleted uranium for use as fuel in commercial reactors. This paper proposes to use the weapons-grade plutonium as fuel in light water reactors. The first such reactor would demonstrate the dual objectives of producing electrical power and denaturing the plutonium to prevent use in nuclear weapons.

The recent Bush-Yeltsin agreement extended the number of warheads that will be cut from the U.S. stockpile to more than 15,000 by Fiscal Year 2003. The ultimate disposition of the weapons-grade material in these weapons must satisfy at least three different goals:

1. Preclude re-use by the super powers.

2. Prevent environmental damage from plutonium contamination.

3. Prevent proliferation from diversion to terrorist groups or non-weapons states.

Once arms reduction has been obtained, a principal goal of the United States should be the mutual destruction of the excess stocks of plutonium in the CIS (Commonwealth of Independent States) and the U.S. to prevent rapid nuclear re-armament. Long-term, safeguarded storage of plutonium is not a desirable option; it doesn't preclude rapid re-armament and it is extremely expensive. Several exotic proposals have been made to dispose of the U.S. stocks, such as rocketing the material to the sun, burying it in deep sea trenches, or contaminating it with high-level waste. However, all of these proposals present environmental and safety concerns. Moreover, such a disposition would be a useless waste of a valuable energy resource.

The most efficient and effective way to dispose of the plutonium stocks would be to use the material as fuel for power-producing nuclear reactors. This use would denature the plutonium and end the proliferation threat by creating high concentrations of fission products and undesirable higher actinides in the fuel. The spent fuel would be a very unatractive target for diversion. The spent fuel could be treated in much the same manner as is planned for uranium-based, commercial reactor fucl (i.e., storage in a National Waste Repository).
Mixed oxide (uranium-plutonium) fuel has been fabricated both in the U.S. and overseas to support nuclear development programs. Fabrication processes used are similar to those for commercial light water reactor fuel. Nevertheless, both the utility industry and the public will need to be convinced by a demonstration that use of such fuels in power-producing reactors is feasible.

The Savannah River Site (SRS) is a logical choice as the location for demonstrating mixed oxide (MOX) fuel fabrication and operating plutonium-denaturing, power-producing reactors. The Site has both a wealth of plutonium experience and a dedicated infrastructure to support all phases of the fuel cycle. SRS is a controlled site, which eliminates proliferation concerns. Furthermore, SRS has existing facilities that can be modified to reduce the overall costs of the proposed project.

Although there are several candidates for a power-producing reactor utilizing plutonium fuel, light water reactors (LWRs) appear to be the most feasible. LWR technology is mature and considerable effort has been invested in enhanced designs that include advanced safety features. Currently, the new generation of advanced LWRs (ALWRs) include passive design plants in the $600 \mathrm{MWe}$ range and evolutionary design plants in the $1200 \mathrm{MWe}$ range. Either plant design can be a pressurized water reactor or a boiling water reactor. Construction and conventional licensing of one of these systems would demonstrate the improved (one-step) procedure that NRC has developed to streamline the cumbersome licensing process. This will provide confidence to utility managers and the general public that improved safety is possible and that a more viable licensing process is now in place.

After successful demonstration of the denaturing of plutonium in an LWR at SRS, either one or a combination of two options could be pursued to fully dispose of the excess plutonium stockpile. The first option would be to use plutonium in commercial power reactors. With approximately 110 such reactors in the U.S., this option would provide the quickest and cheapest means for denaturing the material. However, significant proliferation concerns will have to be overcome in order to provide public confidence in this usage. These concerns center on the presence of plutonium in the unirradiated fuel assemblies. Safeguards would have to be provided. These concerns may limit the viability of this option such that additional capital investment is warranted to construct an energy park of advanced 
LWRs and/or other advanced reactor concepts on a government reservation (like SRS) to consume the plutonium and produce useful electricity. Two or three $600 \mathrm{MWe}$ reactors would denature the postulated excess stockpile within 40 years using a once-through fuel cycle.

A preliminary life cycle study of the energy park concept showed that the excess plutonium could be denatured over the 40-year lifetime at a net cost of $\$ 700$ million (10\% discount rate) or a net protit of $\$ 1.1$ billion (5\% discount rate). In effect, the sale of electricity from the park will offset the costs of the MOX plant and the costs of the reactors as well as the operating expenses.

The use of weapons-plutonium to fuel the two reactor concepts for the tritium-producing New Production Reactor (NPR) was considered. However, the physics characteristics of the Low-Temperature Heavy-Water Reactor (LTHWR) were not as attractive as when fueled with HEU, from a tritium production point-of-view. Decision makers will have to balance the need for efficient tritium production against the opportunity to denature plutonium in the LTHWR. Further consideration is being given by General Atomics to the Modular High-Temperature Gas (cooled) Reactor (MHTGR) for plutonium disposition.

An advanced light water reactor could also provide the option of producing tritium as required to support defense programs. Current weapons stockpile reductions have extended the timing for the production of new tritium to well beyond the year 2000 . Thus, the need for a special purpose tritium production facility becomes questionable. Tritium production in light water reactors has been demonstrated in laboratory scale experiments. With further development of this technology to production status, an advanced LWR could provide a production source to reduce the need for future tritium production facilities. SRS is the logical choice for the site of a tritium-producing ALWR because of its extensive tritium production experience, its tritium extraction infrastructure, and the existing safeguards onsite.

Use of the plutonium stockpile from retired nuclear weapons to fuel light water reactors provides a costeffective, disposal option for this material. Demonstration of this concept at SRS will:

- take advantage of the plutonium experience and available infrastructure,

- allow demonstration of an advanced design for light water reactors,

- test the new, streamlined licensing process,

- provide a means of tritium production when needed, and

- complement a national policy for reprocessing/actinide burning if so adopted. 


\section{Introduction}

\subsection{Purpose}

An excess plutonium stockpile will soon accumulate from the planned reduction of the U.S. nuclear weapons inventory. This report proposes using excess weapons-grade plutonium to generate electricity. Two strategies are presented for consideration by those responsible for the disposition of the plutonium stockpile-

\section{Strategy 1 - Burn Plutonium in Utility LWRs. \\ Strategy 2 - Burn Plutonium in a Government- Owned Energy Park.}

Both of these options include initial phases to prove the viability of the strategies to the public and the commercial nuclear utility industry. The Savannah River Site is proposed as the location of:

- a plutonium fuel fabrication facility,

- an initial LWR (evolutionary or advanced design) for burning excess plutonium,

- an energy park of several LWRs (evolutionary or advanced design) and/or other advanced reactor concepts for burning excess plutonium (Strategy 2 only).

SRS is uniquely qualified to implement either of these strategies in that the Site has a wealth of plutonium experience and a dedicated infrastructure to support all phases of the fuel cycle. The Site is positioned to staff quickly the initial design and analysis effort necessary for a project of this type. Design elements of each strategy will necessarily involve the DOE, reactor vendors, and architect and engineering firms, as well as SRS. Financ.al planning for the proposed strategies would involve federal government agencies (DOE and NRC), the reactor vendors, and the utility industry.

\subsection{Required Number of Plutonium-Fueled Reactors}

The number of LWRs for Strategies 1 and 2 chosen to consume the available excess plutonium ${ }^{1}$ within the operating lifetime of those reactors depends on the reactor power rating and thereactorfuel loading capacity.Strategy 2 requires only two or three $600 \mathrm{MWe}$ reactors to burn the postulated 50 metric tons of excess plutonium stocks in the 40 -year plant design lifetime.

\subsection{Tritium Production Considerations}

Options being considered for future tritium production to satisfy defense needs include the following.

- There are two reactor concepts for a new production reactor, either of which could be fueled with plutonium. Both concepts are well developed and have been selected through a long evaluation process as the prime candidates for new production capability. The Low-Temperature Heavy-Water Reactor (LTHWR) relies on the proven tritium production technology of the SRS reactors. The Modular High-Temperature Gas-cooled Reactor (MHTGR) has the potential to demonstrate advanced gas-cooled reactor technology as well as produce significant amounts of tritium.

- The other option for new isotope production capability is a linear accelerator. Substantial electrical power will be required to support such a facility. A plutonium-burning LWR located at SRS would be an excellent electrical power source if the accelerator were also located at SRS. All the infrastructure to support the facilities would be readily available.

Use of an LWR for plutonium-denaturing provides an additional option for producing tritium as needed. Tritium production has been demonstrated for LWR targets on the laboratory scale. A modest development program ( $\$ 50$ to $\$ 100$ million) would be needed to bring the technology to production status. The tritium target technology issues are discussed in Appendix A.

\subsection{Regulatory Considerations}

\section{Licensing}

The Nuclear Regulatory Commission is currently considering a one-step licensing process for all new nuclear power plants. As emphasized repeatedly in the 1991 ANS San Francisco Winter Meeting's Embedded Topical, "The Next 
Generation of Nuclear Power Plants: A Status Report", streamlining the licensing process is considered essential to begin the; next generation of nuclear power plant orders in the United States. The first new LWR would not only demonstrate advanced technology, but would provide a forum for DOE and NRC to test and optimize the streamlined licensing process as a demonstration to industry of the improvements that have been achieved.

Licensing a plutonium-burning LWR with these improved designs would solidify and verify the overall process and pave the way for future licensing reform. The use of a mixed oxide fuel adds some complexity to the process; but, because the initial LWR with plutonium-burning capability is proposed for a DOE site, it is not expected that this concern would be a major problem.

\section{Siting and Other Concerns}

Any strategy presented in this report would involve location siting and other regulatory concerns. A siting study for a New Production Reactor at SRS, which was perfor.sed using DOE and NRC guidelines, identified several acceptable locations within the inner circle that can be drawn around the existing reactors (i.e., 100 and 200 Area facilities). Some other (non-NRC) permit considerations involve

- Clean Water Act

- wetlands permit (COE404) depending on the plant "footprint" size

- dredging permit (COE10) if the Savannah River is used to transport reactor vessels upriver to the site

- industrial and sanitary waste water permits

- National Pollutions Discharge Elimination System (NPDES) Permits

- emergency diesel generator exhaust

- waste water discharge

- National Historical Law

- anchaeological situ preservation (DOE is committed to this.)

\subsection{Reprocessing Considerations}

In the United States, only the fuel from isotope production reactors in the DOE Nuclear Weapons Complex has been routinely reprocessed after irradiation. In the past, small amounts of LWR fuel have been processed through PUREX-type facilities, but that reprocessing effort ended when the Carter Administration prohibited commercial reactor fuei reprocessing. The Reagan Administration lifted that ban but new commercial fuel has yet to be processed.
The proposed National Waste Repository, to be located at Yucca Mountain, Nevada, will presumably accept the spent L.WR fuel for direct, final disposition. Reprocessing is not under consideration except in connection with the actinide burning question. The traditional reason for fuel reprocessing has been to recover and to subsequently reuse unburned uranium in spent fuel, but with the low market price and plentiful supply of uranium, that argument for reprocessing has weakened. However, the advantages offered by reprocessing with subsequent destruction of the actinides in reactor or accelerator facilities does hold some promise that reprocessing could be revived in the U. S.

The Secretary of Energy requested the National Academy of Science to conduct a special investigation of the advantages offered by and the costs of partitioning (reprocessing) and actinide burning. Actinide burning removes the long-lived actinides from the waste stream by converting them to much shorter-lived fission products. The fission product waste stream would then be vitrified in a plant much like the Defense Waste Processing Facility at SRS. That vitrified waste form would have to last $<1000$ years as compared to $>10,000$ years if the actinides are present.

Reprocessing is not considered as part of either of the strategies proposed in this report. However, should reprocessing and actinide burning become U.S. policy, these processes will extend the use of the plutonium stockpile for energy production. These options are presented in Appendix B.

\subsection{Organization of the Report}

The next section of this report discusses the history of plutonium fuels in both LWRs and SRS production reactors. From this previous work, one can conclude that no technical impediments exist to prevent use of plutonium-based fuels. Section 3 of this report then discusses physics calculations at SRS that specifically treat the use of weapons-grade plutonium as LWR fuel and NPR fuel. Sections 4 and 5 discuss Strategies 1 and 2. Section 6 provides a life-cycle analysis and Section 7 puts forward the recommendations of this study.

\section{References}

1. Parks, P.B., Excess Plutonium Stocks Anticipated from the U.S. and CIS Weapons Build-Down. U.S. DOE Report, WSRC-TR-92-177, Savannah River Site, Aiken, SC 29808 (April 14, 1992). 


\section{Plutonium Fuel Experience}

\subsection{MOX Fuel in LWRs}

H. Bairiot and C. Vandenberg reviewed the use of mixed oxide (MOX) fuel worldwide. Though their remarks were on the use of plutonium recovered through reprocessing LWR fuel or fast breeder reactor (FBR) fuel, Bairiot and Vandenberg provide a concise framework to introduce important issues about reactor fuels made from weaponsgrade plutonium. ${ }^{1}$ This section summarizes their findings.

\subsubsection{Historical Milestones}

In the 1950s, the interest in reprocessing plutonium fuels focused on the fast breeder reactor. The intent was to use the excess plutonium in LWRs for one to two decades before entering into a full breeder economy. In the 1960s, Hanford and Westinghouse Electric Corporation pioneered the research and development program in the U.S. under Atomic Energy Commission sponsorship.

A parallel program in Europe, sponsored by Euratom, focused on plutonium recycling in LWRs and in situ plutonium use in gas-cooled reactors (GCRs). The Belgians and French led the way in the early 1960 s and were joined by Germany (Federal Republic), Italy, and Sweden by the late 1960s.

The U. S. effort expanded to prepare the "Generic Environmental Statement on the Use of Mixed Oxides" (GESMO) in the early 1970s. However, the Carter Administration decided to defer commercial nuclear fuel reprocessing indefinitely and the GESMO effort stopped at its draft preparation.

The Europeans also decreased their reprocessing efforts in the LWR industry until only Belgium and the German Federal Republic continued with LWR plutonium fuel programs by the early 1980s. The British, French, and Japanese efforts on FBR programs continued.

\subsubsection{Current and Projected MOX Fuel Use}

The most recent efforts are best described by a direct quote from Bairiot and Vandenberg:

Over the last few years, with the successful commercial operation of the Cogema reprocessing plant and the delays foreseen in the large scale deployment of FBRs, concerns about plutonium utilization have re-emerged. The market price of plutonium has dropped and the quantities available exceed the demand. An increasing number of utilities are, therefore, now faced with the choice of either stockpiling the plutonium or recycling it in their own power plants.

As of 1987, most utilities in Europe and Japan were facing the commercial phase of plutonium recycling in LWRs. Belgium prepared itself by loading without interruption since 1963 increasing amounts of MOX fuel in the BR3 PWR culminating in a proportion of $70 \%$ MOX fuel in the 1986 reload....

Switzerland has pursued a motivated policy by loading MOX fuel in Beznau steadily since 1984. This loading has been preceded by a demonstration incorporation of MOX assemblies in Beznau 2.

In the Federal Republic of Germany, the industrial MOX utilization started in 1981, after a demonstration period from 1968 to $1977 . .$. It is based on a progressive implementation of an industrial manufacturing capability at ALDIM.

The French utility, Electricité de France (EDF), decided to recycle plutonium on a commercial basis (1985) and a group of 16 plants are being licensed with this aim.... The decision was based on demonstration assemblies incorporated in the Chooz PWR in 1974 and 1975 and on the assessment of the industrial background and capability of COMMOX.

In Japan. a three step programme has been launched, starting ifi 1986 with a small scale demonstration programme in Tsuruga 1 and Mihama 1, to be followed by a large scale demonstration programme in one BWR and one PWR, each of the $800 \mathrm{MW}(\mathrm{E})$ class, and culminating in the commercial use of MOX around 1997 in 6 BWRs and 6 PWRs of the $1000 \mathrm{MW}(\mathrm{E})$ range. This activity can partially benefit from the advanced thermal reactor (ATR) development activity being pursued by the Power Reactor and Nuclear Fuel Development Corporation (PNC) since 1972 and from close relationship with the European achievements. ${ }^{1}$ 
The European and Japanese programs described above demonstrate an accepting attitude on the part of the involved governments to a program of burning plutonium fuels.

THEY ARE DOING IT.

During April and May of 1992, the trade press was filled with articles about German MOX technology transfer to the Commonwealth of Independent States (CIS). The purpose of the technology transfer was to assist the former Soviet states with burning weapons-grade plutonium that will accumulate during their weapons reduction programs. Though it is uncertain that such a program will actually occur, it is clear that the CIS is actively considering reducing their excess plutonium stockpile by burning it in their LWRs.

\subsubsection{Characteristics of MOX Fuels}

Though primarily an alpha emitter, plutonium also emits neutrons, $x$-rays, gamma rays, and beta particles. Because most of the radiation will not penetrate, the radiological hazard is essentially blocked once the plutonium is in fuel rods. Weapons-grade plutonium is mostly Pu-239, with $<6$ wt \% Pu-240 and <0.8 wt \% Pu-241. These higher weight isotopes are far more prevalent in plutonium recovered from LWRs; typically Pu-238 at $1.5 \mathrm{wt} \%, \mathrm{Pu}-239$ at $58 \mathrm{wt} \%$, Pu-240 at 23 wt \%, Pu-24l at 13 wt \%, and Pu-242 at 5.2 wt $\%$. The neutron emission rate is essentially constant in time and depends on the isotopic mix. The gamma emission rate is dominated by the decay of the Pu-241 daughter product Am-241. Each year, $4.7 \%$ of the Pu-241 decays to Am-241 that emits low-energy gamma radiation.

The principal hazard in MOX fuel fabrication is in the glove box lines in which plutonium fuel is handled. After prolonged storage, the use of plutonium oxide becomes economically impractical without subjecting it to a further reprocessing step to remove the Am-241 buildup. The cost of such reconditioning essentially doubles reprocessing costs.

It is the reason why plutonium recovered from LWRs should not be stored as $\mathrm{PuO}_{2}$ powder as delivered by the reprocessing plant but should be manufactured into MOX fuel rods or even assemblies as soon as possible. Three years of $\mathrm{LWR} \mathrm{PuO}_{2}$ storage is considered to be the practical limit. ${ }^{1}$

$\mathrm{PuO}_{2}$ obtained from weapons returns should be much easier to handle because the Pu-241 content is much less than in the $\mathrm{PuO}_{2}$ from recovered $\mathrm{LWR}$ fuel.

\section{Reactor Design and Safety}

Table V of of the Bairiot and Vandenberg document (see Table 2.1) succinctly describes the principal effects of MOX fuels on the primary reactor design and safety characteris-. tics of LWRs.' Perusal of Table 2.1 shows that LWRs with MOX fuels behave very much like LWRs with uranium fuels. The differences are of degree, not of kind. These differences have to be taken into account but do not pose difficult design or operating problems.

A MOX fuel rod can be designed to the same quality standard as a uranium one in the same cladding. The $U$ fuel assemblies and the MOX fuel assemblies do have therefore the same hardware structure and the same geometry, resulting in identical assembly structure, mechanical design and identical thermohydraulic design. The design criteria an LWR core has to meet are the same whether loaded with U or partially with MOX fuel. These criteria must guarantee that:

(1) Values of the physical characteristics of the core are within the limits taken into account in the safety analyses. If this were not the case, for some licensing basis events, those safety analyses would have to be re-evaluated.

(2) Fuel performance (power level, discharge burn up, cycle length) is not deteriorated by the substitution of some U fuel by MOX fuel...

Practically, if one limits the insertion of MOX rods to one third of the reload fuel for each reactor cycle, there is no major licensing problem for the utilities. For the MOX fuel vendor, this involves adequate know-how and design work to ensure that the uncertainty margin penal ties are not larger than for a uranium core. From the preceding considerations, one can conclude that any LWR can be loaded with MOX fuel assemblies. The choice and quantity of MOX fuel to be reloaded depends on external considerations such as licensing limitations and on considerations that are under the responsibility of the utilities (e.g., general policy, contractual commitments).

\section{MOX Fuel Fabrication}

As of 1989, Bairiot and Vandenberg described the "reference fabrication processes" for MOX fuel as OCOM in the Federal Republic of Germany and MINAS in Belgium. Both processes are based on mixing and milling a master blend of 
Tahle 2.1. Comparison of Uranium and MOX Nuclear Design Characteristics**

\begin{tabular}{|c|c|c|c|}
\hline Earametic & Plutonium Core & Reason for Difference & Consequence \\
\hline $\begin{array}{l}\text { Moderator temperature } \\
\text { coefficient }\end{array}$ & More negative & $\begin{array}{l}\text { Increased resonance } \\
\text { absorption and spec- } \\
\text { tral shifts }\end{array}$ & $\begin{array}{l}\text { Improved stability and transient } \\
\text { characteristics except for 'cold } \\
\text { water' transients" }\end{array}$ \\
\hline Doppler coefficient & More negative & Pu-240 resonance & Improved transient characteristics \\
\hline Installed reactivity & Reduced & Reduced depletion rate & Higher reactivity lifetime capabilit \\
\hline Control rod requirements & Increased & $\begin{array}{l}\text { Larger moderator and } \\
\text { Doppler coefficients }\end{array}$ & $\begin{array}{l}\text { Possible increase in number of } \\
\text { control rods }\end{array}$ \\
\hline Boron worth & Reduced & Thermal flux reduced & $\begin{array}{l}\text { Possible increase in number of } \\
\text { control rods }\end{array}$ \\
\hline Xenon worth & Reriuced & Thermal flux reduced & $\begin{array}{l}\text { More boron used for cold or hot } \\
\text { reactivity swing }\end{array}$ \\
\hline Gd poison efficiency & Reduced & Thermal flux reduced & Improved stability \\
\hline Local power peaking & Reduced & Increased water worth & Fuel assembly design \\
\hline Delayed neutron fraction & Reduced & $\beta P u<\beta U$ & $\begin{array}{l}\text { Rod ejection accidents (PWR) } \\
\text { Rod drop accidents (BWR) }\end{array}$ \\
\hline
\end{tabular}

- PWR: Steam line break.

QUALIFICATIONS:

BWR: Loss of feedwater heating. Generator load rejection without condenser bypass.

(1) Effects can be mitigated by changes in design.

(2) Plutonium isotopic composition influences the parameters.

Turbine trip without bypass

** Table V in Reference 1

$30 \% \mathrm{PuO}_{2}$ and $70 \% \mathrm{UO}_{2}$ powders. The pellets produced by these processes do contain $30 \% \mathrm{PuO}_{2}$ regions of less than $100 \mu \mathrm{m}$ in a $\mathrm{UO}_{2}$ matrix. The product is $99 \%$ soluble in nitric acid as fabricated and almost entirely soluble after irradiation.

The French and Japanese processes are different.

Organizations dealing mainly with FBR fuel, namely CEA in France and PNC in Japan, have not teveloped a specific manufacturing process for $L W R$... MOX fuel but apply as such the FBR fuel fabrication route, namely a complete dilution of the plutonium in the matrix. In the French process, sometimes referred to as MIGRA (micronization-granulation), the $\mathrm{PuO}_{2}$ powder is blended by micronization with all the $\mathrm{UO}_{2}$ necessary to obtain the required pellet enrichment. In the Japanese process, it is a co-converted $\mathrm{UO}_{2}-50 \% \mathrm{PuO}_{2}$ (denitrated by microwave) which is co-milled with the adequate amount of $\mathrm{UO}_{2}$ to reach the required pellet enrichment. Both types of MOX fuel have properties quite different from MIMAS and OCOM fuel, which should properly be taken into account in fuel design and safety evaluation. In particular, the Doppler coefficient is weakened in this fuel compared to MIMAS or OCOM fuel. ${ }^{1}$

\subsubsection{MOX Fuel Behavior}

Again, quoting from Bairiot and Vandenberg:

MOX fuel incorporated in power reactor cores has behaved outstandingly well, usually better than the uranium fuel also present. No unexpected licensing problems have been encountered. Potential limits to the 
quantity of MOX fuel that can be loaded in some types of reactors have been determined, and ways of circumventing these limits have been investigated. In addition, well characterized assemblies irradiated to high burn ups have demonstrated that MOX fuel can satisfy the general trend towards a progressive increase in discharge burnups...'

In summary, Bairiot and Vandenberg make the claim that the behavior of MOX fuel is as good as uranium fuel.

This fact justifies immediate and massive MOX fuel utilization by utilities owning adequate plutonium resources and having access to the required technology; it is the case for... Belgium, France, the Federal Republic of Germany and Switzerland, and it will be the case in the near future for... Japan.'

The foregoing remarks of this section make it clear that no technical reasons prevent burning plutonium in $L W R s$. The constraints are mainly from economic and political considerations.

\subsection{Plutonium Experience at SRS}

Fuel assemblies containing plutonium have been manufactured and irradiated in Savannah River Site production reactors on at least three different occasions. This experience demonstrates the plutonium handling and fabrication capability at SRS for use in the low-temperature, heavywater reactors. Three somewhat different assemblies were created to contain the plutonium and were designated as Mark 18-A, Mark 41, and Mark 42.

The Mark 18-A assemblies (sometimes called Plush-1) were made both by powder metallurgy techniques to produce $\mathrm{PuO}_{2}$ and $\mathrm{Al}-1100$ cermets, and by casting $\mathrm{Al}-\mathrm{Pu}$ alloy metal ingots. ${ }^{2}$ These were both extruded into target tubes and clad with Al-6063. These plutonium targets were then irradiated over an extended period to maintain the Cf-252 content first produced in the Californium - I campaign of the late 1960s. By April of 1974, the target cores had completed five years of extended service resulting in an accumulated fission density of $5.8 \times 10^{20}$ fissions $/ \mathrm{cm}^{3}$ in the cermet type cores and $1.5 \times 10^{20}$ in the casit cores. ${ }^{2}$ The cladding had been exposed to peak neutron flueucris of about $2 \times 10^{23} \mathrm{n} / \mathrm{cm}^{2}$ (thermal) and $3 \times 10^{22} \mathrm{n} / \mathrm{cm}^{2}(\mathrm{E}>0.1 \mathrm{MeV})$. The total swelling in the cermet cores was estimated to have ranged from about $2.6 \%$ to $5.4 \%$ of the core volume, principally from fission product creation. The total cladding swelling was estimated to have been about $0.7 \%$ of the cladding volume. The strain from these expansions was expected to induce cladding cracking with further exposure.
To prevent this, the Mark 18-A assemblies were moved to the low flux peripheral regions of the reactor, where negligible damage was anticipated.

The Mark 41 target tubes were also made as extrusions of cermet cores, which were manufactured by powder metallurgy techniques. ${ }^{3}$ These, targets were intended to enhance the $\mathrm{Pu}-242$ contents of the plutonium by way of neutron addition. The design estimates of the exposure accumulated in the irradiations were $5.9 \times 10^{20}$ fissions $/ \mathrm{cm}^{3}, 1 \times 10^{22}$ $\mathrm{n} / \mathrm{cm}^{2}$ thermal fluence and $0.5 \times 10^{22} \mathrm{n} / \mathrm{cm}^{2}$ fast fluence $(\mathrm{E}>$ $0.1 \mathrm{MeV}$ ). A total core swelling of, at most, 3.8 volume \% was anticipated. The Al-6063 cladding used on these targets withstood this amount of swelling without failure.

The Mark 42 assemblies were also used to make $\mathrm{Pu}-242$ in an extended irradiation of over five years." Three nested target tubes ware made for each assembly. Each tube had an effective core length of about 150 inches. The three plutonium tubes were combined with either an inner lithium target tube or an inner housing tube (aluminum only) to provide reactivity control.

Up to 54 Mark 42 assemblies were irradiated in five different reactor cycles beginning with the P-11.1 subcycle. ${ }^{5}$ The goal was to produce $15 \mathrm{~kg}$ of plutonium with an isotopic content of at least $86 \%$ Pu-242 for the Los Alamos National Laboratory (LANL). The reactivity was inigh enough for the Mark 42 to serve as a fuel assembly in the first cycle (that is, it replaced a highly-enriched Mark 16B fuel assembly in the central regions of the reactor, 54 assemblies in all). In the intermediate cycles, pairs of fuel and target positions were used (that is, one Mark 16B fuel asserrioly was replaced with a previously irradiated Mark 42 assembly and a Mark 31 depleted uranium target assembly was also replaced with a previously irradiated Mark 42 assembly). During the fifth cycle, the reactivity of Mark 42 assemblies had been reduced sufficiently so that all had to be placed in target positions.

The Mark 42 plutonium tubes had areas of higher-than-normal density, which increased the local heat flux and cladding temperature. Cladding temperature was maintained below $200^{\circ} \mathrm{C}$ to prevent rapid intergranular corrosion of the Al-6063 alloy cladding.

Two assemhlies were removed from the reactor before completing the planned irradiation because of suspected component damage. ${ }^{5}$ One assembly was damaged when the top portion of its housing tube was bent during a discharge operation. The other assembly was removed because of an indicated low flow but, upon inspection, no cause for the low now was discovered. All other assemblies completed 
the irradiation without incident. The total fast neutron fluence was described as $2 \times 10^{22} \mathrm{n} / \mathrm{cm}^{2}(\mathrm{E}>0.1 \mathrm{MeV})^{3}$ that was $2 / 3$ of that experienced by the Mark 18-A assemblies in their irradiation. No failures occurred from swelling and subsequent cladding cracking.

It should be pointed out that the aluminum technology used for the Savannah River Site fuels and targets render them unsuitable for high-temperature electricity producers such as LWRs. Only the MOX-type fuels described in the previous section can be used in LWRs.

\section{References}

1. H. Bairiot and C. Vandenburg.Nuclear Fuel Cycles in the 1990s and Beyond the Century: Some Trends and
Foreseeable Problems. Technical Reports Series, International Atomic Energy Agency, Vienna, Austria (1989).

2. T. H. Gould. Irradiation Effects in Plush-1 Target Tubes. DPST-74-283, Savannah River Site, Aiken, SC 29808 (March 19, 1974).

3. T. H. Gould. Irradiation Effects in Mark 41 Targets. USDOE Report DPST-74-387, Savannah River Site, Aiken, SC 29808 (March 19, 1974).

4. R. P. Taylor. Irradiation of Mark 42 Assemblies. USDOE Report DPSOX-9770, Savannah River Site, Aiken, SC 29808 (August 1, 1980).

5. K. A. Meassura. Irradiation of Mark 42 Assemblies. USDOE Report DPSOX-9770, Savannah River Site, Aiken, SC 29808 (August 10, 1984). 


\section{Consumption of Plutonium in Reactors}

\subsection{Initial LWR at SRS}

In the GESMO report ${ }^{1}$, it was assumed that the plutonium in MOX fuel would come entirely from reprocessing power reactor fuel. This led to specifying plutonium in reload MOX fuel in terms of what could be produced in an equilibrium fuel cycle. This, in turn, led to specifying MOX fuel (assuming uniform fuel in reload) as containing less than $1.8 \mathrm{wt} \%$ total plutonium in heavy metal in the as-charged fuel.

In other studies referenced in that report ${ }^{1}$, reload fuel assemblies consisted of a combination of MOX fuel assemblies and uranium fuel assemblies. In these cases, the MOX fuel assemblies contained up to $4.2 \mathrm{wt} \%$ plutonium in heavy metal. This content was required to obtain the same fuel exposure $(33,000 \mathrm{MWD} / \mathrm{MTHM})$ as obtained with slightly-enriched uranium (SEU) fuel. It was repeatedly stated in the report that there was no technical reason why higher plutonium contents could not be used. For example, referring to the uniform MOX reload upper limit of $1.8 \mathrm{wt} \%$ plutonium, it was stated that "this concentration should not be considered as a limitation on the amount of plutonium that could be safely and economically used in LWRs".

With the above background, it was decided to (a) assume uniform MOX fuel for reload, and (b) assume that $1 / 3$ of the core would be reloaded per year (this 1/3-core reload strategy was also assumed in the GESMO report). It was further decided to determine the reload MOX-fuel plutonium content based on (a) matching the long-term reactivity transient in a SEU-fueled PWR, and (b) obtaining about the same discharge fuel exposure as in a SEU-fueled PWR.

A lattice physics model using the GLASS code was used to do the calculations. The details of the calculations are given in Reference 2. The result was that the MOX reload fuel contained $3.3 \mathrm{wt} \%$ weapons plutonium in heavy metal (the uranium with which it was mixed was assumed to be $0.2 \%$ U-25.5). The fuel exposure of the reload fuel after one year was the same as in the reference case using SEU; but the discharge exposure after three years was $\sim 31,500 \mathrm{MWD} /$ MTHM, somewhat less than in the reference case using SEU (33,400 MWD/MTHM).

If a single LWR of $600 \mathrm{MWe}$ ( $1818 \mathrm{MW}$ th) is assumed with a capacity factor of $75 \%$, the thermal exposure per year would be $498 \mathrm{GWD}$. From the physics calculations, the 1/3-core reload of fuel each year would contain $522 \mathrm{~kg}$ of weapons plutonium (containing $492 \mathrm{~kg}$ of $\mathrm{Pu}-239$ ). Because there is $3.3 \mathrm{wt} \%$ weapons-grade plutonium in the reload fuel, the fuel requirements per year would be $15.8 \mathrm{MTHM}$, or 17.9 MT of MOX fuel.

Presumably the fuel requirements would be similar for a BWR, just scaling by MWDth/year if necessary.

\subsection{Utility LWRs}

A quantity of $50 \mathrm{MT}$ of weapons-grade plutonium is postulated as being available for use in plutonium fuel-burning reactors. For estimating the capacity and cost of the MOX fuel fabrication plant, the number of reactors involved is not considered, but, rather the postulated $50 \mathrm{MT}$ of weapons plutonium to be consumed over the postulated 40-year period. Thus, the plant should process $1.25 \mathrm{MT}$ or $1250 \mathrm{~kg}$ of weapons plutonium per year. To convert this to a quantity of MOX fuel, an enrichment must be assumed. A reasonable lower limit would be the $1.8 \mathrm{wt} \%$ plutonium in heavy metal discussed in the GESMO report, while a reasonable upper limit would be the $3.3 \mathrm{wt} \%$ plutonium in heavy metal developed in the prior section. Thus, the yearly throughput would range from $38 \mathrm{MT}$ to $69 \mathrm{MT}$ of heavy metal, or 43 MT to 79 MT of MOX fuel. Even at the higher value, this is smaller than the $120 \mathrm{MT} /$ year MOX fuel plant under construction in Germany. ${ }^{3}$

\subsection{Multiple LWRs with Reprocess- ing and Actinide Burning}

Multiple LWRs are assumed with the fueling requirements just discussed in Section 3.1 and Section 3.2. For each reactor, the discharged fuel each year (17.9 MT of MOX fuel) would contain the following calculated isotopes.

\begin{tabular}{lc} 
Isotope & Kg Discharged \\
\hline Pu-239 & 240.0 \\
Pu-240 & 107.5 \\
Pu-241 & 66.8 \\
Pu-242 & 17.6 \\
Pu-238 & 1.50 \\
Np-237 & 2.25 \\
Am-241 & 2.49
\end{tabular}




\section{Isotope}

$\begin{array}{ll}\mathrm{Am}-243 & 4.16 \\ \mathrm{Cm}-242 & 0.76 \\ \mathrm{Cm}-243 & 0.03 \\ \mathrm{Cm}-244 & 1.74\end{array}$

If the fuel were subjected to reprocessing, the neptunium, americium, and curium would be destined for the actinide burner (or special isolated disposal if the burner were not employed). The recovered plutonium could be used partly to fuel the actinide burner (if it is a fast reactor), with the remainder available to refuel the LWRs. For the moment, the pcrential plutonium requirements for an integral fast reactor (IFR) actinide burner will be disregarded and it is assumed that all of the recovered plutonium will be recycled in LWRs.

On an equilibrium fuel cycle basis with recovered plutonium from a reactor being used to reduce weapons plutonium to refuel the same reactor, the approximation is made that fissile plutonium from reprocessing can replace fissile plutonium in weapons plutonium on a kilogram basis regardless of admixed non-fissile plutonium isotopes. Thus, if there are no losses in reprocessing and fabrication, the 307 $\mathrm{kg}$ of Pu-239 and Pu-241 recovered per year from one reactor would reduce the draw of $492 \mathrm{~kg}$ of Pu-239 from the weapons plutonium stockpile to about $185 \mathrm{~kg}$ of Pu-239.

This option is considered in some detail in Appendix B.

\subsection{New Production Reactor}

Weapons plutonium can be used rather than HEU to fuel a LTHWR. Presumably $\mathrm{PuO}_{2}$ would be used in powder metallurgy fabrication of plutonium-containing aluminum fuel tubes, as described in Section 2. The core design is somewhat less satisfactory than when using HEU, because $\mathrm{Li}-6$ in the outer targets must be reduced and $\mathrm{Li}-6$ in the inner targets must be increased to achieve acceptable temperature coefficients. This, in turn, damages the longterm reactivity transient. A mid-cycle shutdown to replace the inner target is necessary to achieve a final exposure of 70 MWD/assy- $\mathrm{ft}$, which is less than the 80-100 MWD/assy-ft achievable with HEU without a mid-cycle shutdown. Another minor disadvantage of using plutonium fuel is that productivity (gm T/MWD) is several percent lower than with HEU.

The fuel assembly whose core characteristics are discussed above, contained $203.6 \mathrm{gm} / \mathrm{ft}$ of weapons plutonium (192 $\mathrm{gm} / \mathrm{ft}$ of Pu-239). After $70 \mathrm{MWD} / \mathrm{ft}$ of exposure, the fuel assembly is calculated to contain $131.7 \mathrm{gm} / \mathrm{ft}$ of total plutonium (88.5 gm/ft of $\mathrm{Pu}-239)$.

The physics differences discussed above make the use of weapons plutonium somewhat unattractive compared to the use of HEU. The extra fuel fabrication costs imposed by the use of plutonium also favor the use of HEU rather than weapons plutonium. The LTHWR can use HEU from retired weapons directly without separative work dilution. If an LTHWR were to be constructed, the need for efficient tritium production would have to be balanced against the opportunity to denature plutonium. However, that decision does not need to be made now, in view of the recent deferral of NPR decisions by DOE.

Similar considerations are under study by General Atomics for the MHTGR-NPR. The results will determine the viability of this concept for plutonium denaturing.

\section{References}

1. Final Generic Environmental Statement of the Use of Recycled Plutonium in Mixed Oxide Fuels in Light Water Cooled Reactors. U. S. Nuclear Regulatory Commission, NUREG-0002 (August 1976).

2. W. E. Graves. Plutonium Reload Requirements for PFBR. SRT-APG-920047 (May 21, 1992).

3. Nuclear Fuel, p 6 (June 22, 1992). 


\section{Strategy 1 - Utility Use of Plutonium Fuel}

\subsection{Phase 1 - Fuel Cycle Demonstration}

\subsubsection{MOX Fuel Plant at SRS}

Several different plutonium compounds have been investigated for application in fuel rods. These forms include plutonium-uranium-nitrides, - carbides, and -oxides. The extensive research and development work on these materials clearly shows that mixed oxide fuel has the most promise for near- and intermediate-term applications. ${ }^{1}$ Numerous MOX fuel designs have been investigated including compacted/sintered pellets and vibro-packed microspheres or powders. Of these, the pelletized fuel is the most promising for near-term applications.

The MOX fuel manufacturing process is, to a large extent, similar to the process used to manufacture $\mathrm{UO}_{2}$ fuel for power reactors. The extensive knowledge base acquired through 30 years of industrial manufacturing experience is directly applicable to MOX fuel fabrication except for the added consideration of the plutonium radiological hazard. The radiological danger of plutonium dust, as observed through factory experience, provides the major impetus to automate plutonium manufacturing facilities. Remotely operated, automated fabrication facilities are necessary to meet the safeguards and ALARA personnel protection requirements, and to ensure improved nuclear material accountability and control techniques. MOX facilities ${ }^{2-3}$ mechanization has gradually led to production operations with minimal human contact or intervention.

\section{MOX Fuel Fabrication/Flowchart}

MOX fuel can be manufactured using basic powder metallurgical (PM) methods. ${ }^{4}$ (See Figure 4.1 for a process diagram.) Because plutonium oxide is not completely soluble in nitric acid, some fabricators of mixed oxides have modified the basic or reference PM process to obtain a higher solubility oxide. The two main fabrication routes that were developed to manufacture soluble MOX fuel pellets were co-milling and co-conversion of oxide powders. In co-milling, the plutonium oxide and uranium oxide powders are co-milled to give a homogeneous mixture that forms a solid solution during subsequent sintering operations. Co-conversion plants produce a $(\mathrm{U}, \mathrm{Pu}) \mathrm{O}_{2}$ precipitate feed powder that replaces the co-milling step for homogeniza- tion. The cc-conversion prowess produces a powder that can easily be reprocessed in nitric solutions. Co-conversion processes are being actively developed in Japan and in France. ${ }^{5}$ Because the proposed MOX fuel strategy does not involve recycled fuel/plutonium, the reference process will be used to make the fuel pellets.

Figure 4.1 shows both the reference process that uses plutonium oxide and uranium oxide powders and the co-milling process that produces the more soluble oxide powder.

In the proposed MOX facility for SRS, the weapons-grade plutonium pits will be converted to $\mathrm{PuO}_{2}$ powder by 3 dissolution process ${ }^{6}$ shown in Figure 4.2. Depleted uranium trioxide powder, presently stored in drums at SRS, will be converted to $\mathrm{UO}_{2}$ by hydrogen reduction as shown in Figure 4.3. These powders will provide the feed material for the MOX plant. As shown in Figure 4.1 for the reference process, free-flowing depleted $\mathrm{UO}_{2}$ and $\mathrm{PuO}_{2}$ powders are first blended to obtain a homogeneous mixture. The powders are granulated, compacted into green pellets using automatic presses, and then sintered at high temperatures. The sintered pellets are then centerless ground to specified dimensions. All rejects are re-ground and recycled.

A pellet column is prepared and dried in a furnace. The column is then loaded into zircaloy tubes with a spring atop the pellets, outgassed, the tube backfilled with helium and moisture getters, and then seal welded. The tubes are assembled into reactor fuel assemblies in a manner similar to the LWR fuel assemblies. The assemblies are then packaged for shipment to the reactor area.

\section{Cost Estimate}

Cost estimates for this study were made using the PC-based Freiman Analysis of System Technique (FAST). This cost analysis technique, also used by DOE, provides a uniform approach to cost estimating for the reconfiguration cost throughout the DOE Nuclear Weapons Complex. The technique involves parametric cost estimating, which is the process of transforming physical characteristics for a process through statistically established relationships. As insufficient design data exists for the proposed facility, costs estimates were derived from current SRS data using Defense Waste Processing Facility Project 1780 as the reference (calibration) project. 

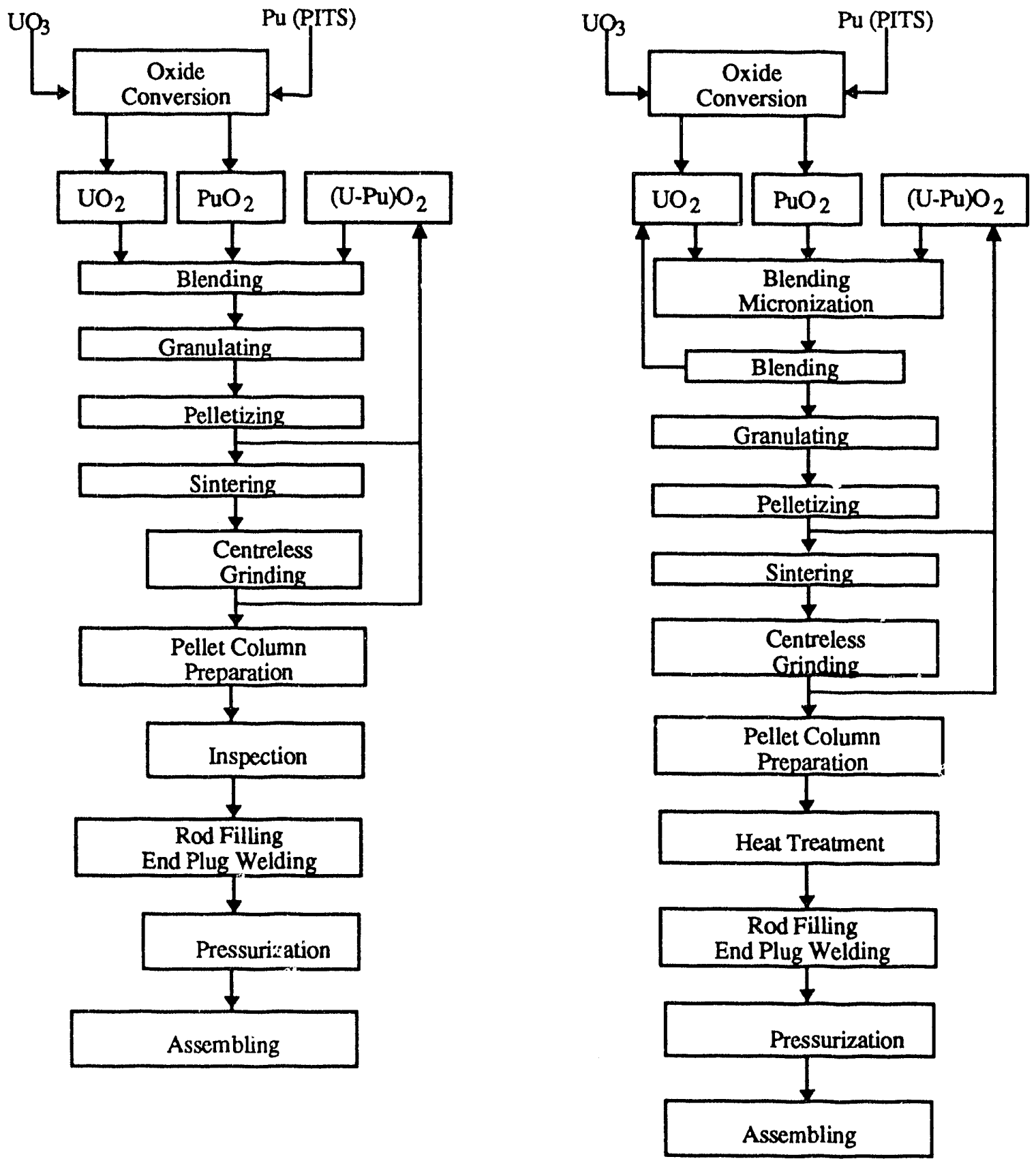
a) Reference MOX Fuel
Fabrication Process

b) New MOX Fuel Fabrication Process (MIMAS \& OCOM)

Figure 4.1. Comparison of the Reference and the New MOX Manufacturing Processes 


\section{"Greenfield" Facility}

Cost estimation was conducted using the FAST technique for a 60-70 MTHM/year fuel facility. The facility occupies a $150,000 \mathrm{ft}^{2}$ building that includes $25,000 \mathrm{ft}^{2}$ of office space. Manufacturing operations are: $\mathrm{UO}_{2}$ and $\mathrm{PuO}_{2}$ powcier conversion; pellet fabrication; fuel assembly; and inspection and shipping. The facility includes parallel lines for redundancy. The building is designed to expand if fuel for additional reactors is required. A high spot cost of $\$ 680$ million was estimated for a fully automated 60-70 MTHM/ year "greenfield" MOX fuel fabrication facility. ${ }^{6}$ This estimate includes $\$ 100$ million for the $\mathrm{UO}_{3}$ to $\mathrm{UO}_{2}$ conversion, $\$ 205$ million for plutonium to $\mathrm{PuO}_{2}$ conversion, and $\$ 375$ million for pellet fabrication and fucl assembly.
For one $600 \mathrm{MWe}$ reactor on site, the required throughput for the MOX facility is $\sim 15-17$ MTHM/year. The above plant could operate on a one-shift basis and produce the required fuel for the initial reactor. The annual operating costs for this plant on a one-shift basis is expected to be $\$ 30$ million based on 300 Area operating costs for 1991.7

The cost of MOX plants in Europe tends to be somewhat less expensive than the above "greenfield" facility. Siemens AG is building a 120-MTHM/yr capacity MOX plant in Hanau, Germany, at a cost of about $\$ 500$ million. ${ }^{19}$ British Nuclear Fuels is reported to be considering construction of a MOX plant at Sellafield with a 100-MTHM/year capacity for approximately $\$ 400$ million. ${ }^{19}$ The reason for the higher cost of the SRS "greenfield" facility may be the expense of conforming with the rigorous safety standards imposed by DOE orders on all new facilities constructed at DOE sites.

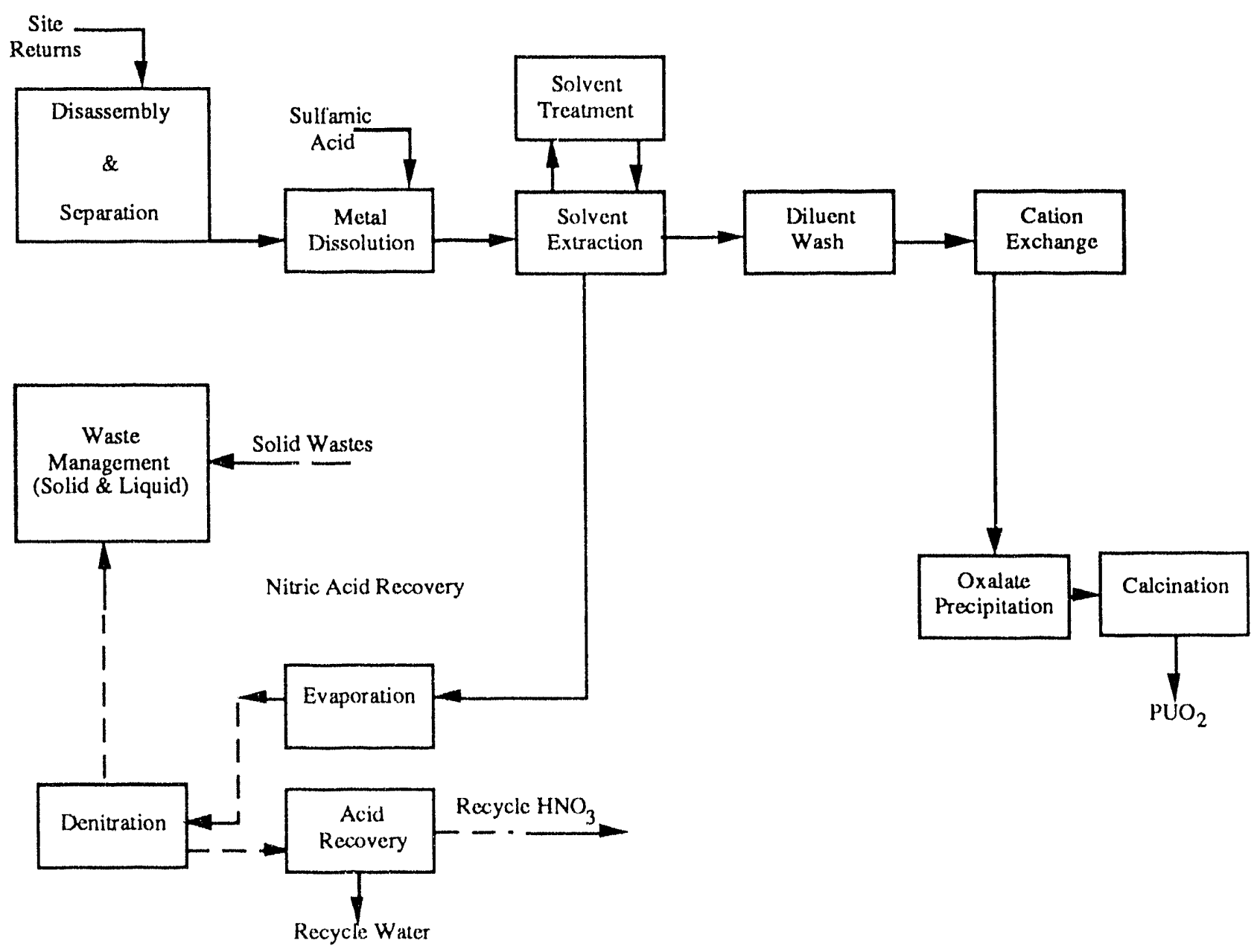

Figure 4.2. Site Returns Processing 


\section{Modifying Existing Facilities}

An opportunity exists to adapt some existing facilities to manufacture fuel. Using existing SRS facilities in F Area offers a unique advantage in both cost and schedule. The 235-F facility has a dedicated personnel intrusion detection alarm system (PIDAS) zone, contains its own emergency equipment, ventilation equipment, sand filter, and stack. The main building is a hardened structure with two vault areas. The lower level of the 235-F facility could be used to assemble fuel while the second level could be used to fabricate pellets, offering advantages from accountability and safeguards points-of-view in that the pellets do not leave the facility. Alternatively, Barnwell Nuclear Fuel Plant (BNFP/AGNS), an idled separations facility which meets or exceeds DOE/NRC design requirements for shipping, receiving, storage, and processing, may also be modified. This facility, which has a 100-acre processing area, can be readily adapted to plutonium oxide fuel manufacturing.

The potential cost benefits of using existing SRS facilities (presently candidates for retirement) or the AGNS facility in Barnwell were also estimated. The cost for a 60-70 MTHM/year fuel facility using modified SRS facilities is

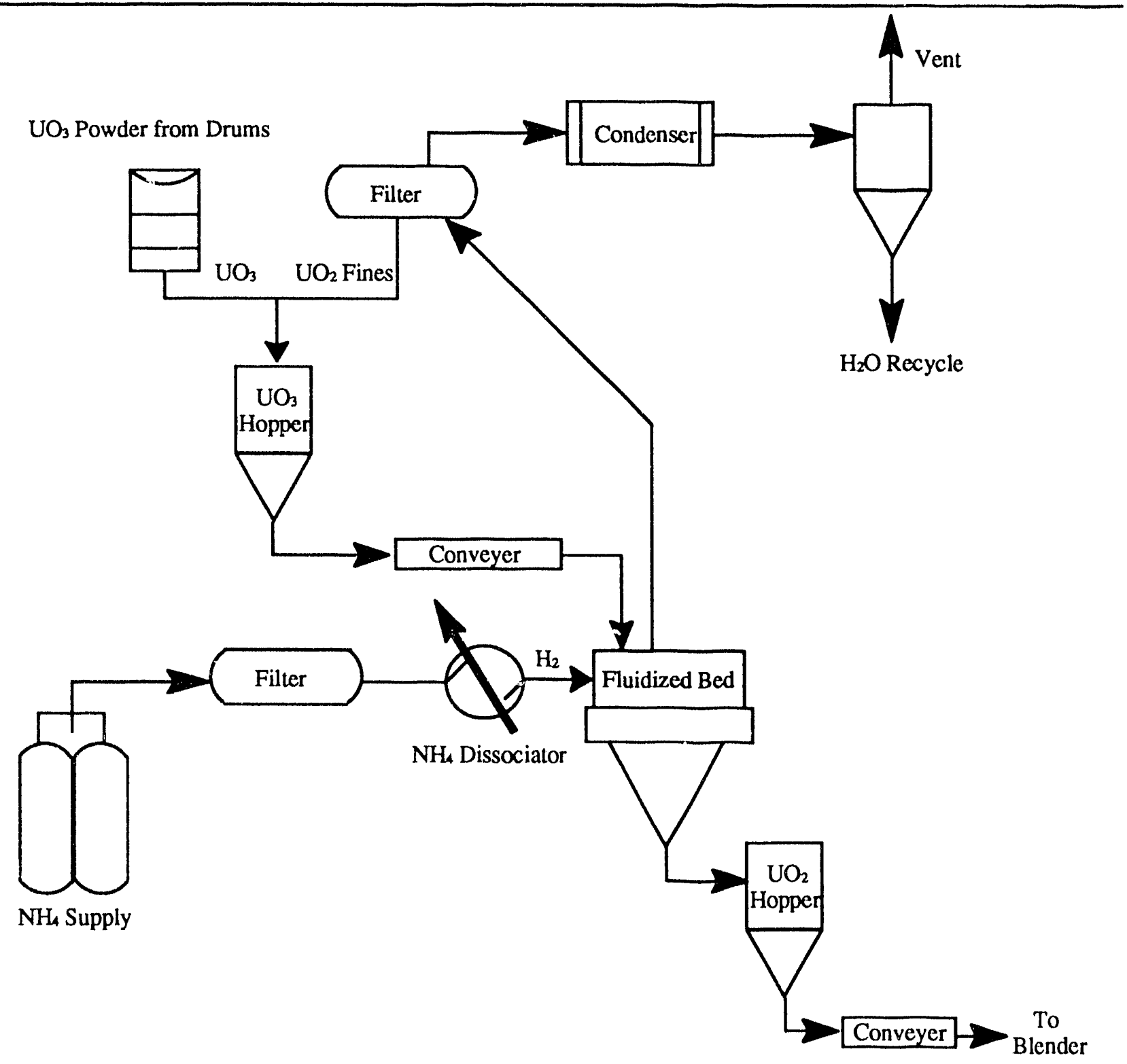

Figure 4.3. UO 2 Conversion Process 
estimated to be $\$ 200$ million while that using the AGNS modification is $\$ 260$ million as compared to the "greenfield" facility costs of $\$ 680$ million. For this plant, a cost reduction of $-60 \%$ is achieved using a modified AGNS facility whereas a cost reduction of $\sim 70 \%$ is achieved using a modified SRS facility. The annual operating costs for this plant is also expected to be $\sim \$ 30$ million per year.

\subsubsection{Initial LWR at SRS}

The object of Strategy 1 is to demonstrate that weaponsgrade plutonium can be burned in MOX fuel, using commercial light water reactor technology. Such a demonstration would prove that utility-owned LWRs can be used to eliminate weapons-grade plutonium while, at the same time, generate electric power to help meet consumer needs. Phase 1 of this strategy involves constructing and operating an LWR at SRS to demonstrate the plutonium fuel burning concept. As envisioned, the plutonium fuel burner would be an advanced light water reactor (ALWR), which could be either a passive design plant in the 600 MWe range or an evolutionary design plant in the $1200 \mathrm{MWe}$ range.

The new generation of ALWRs includes both pressurized water reactor (PWR) and boiling water reactor (BWR) plants, either of which can be passive or evolutionary in terms of design. The major differences betwcen these two diesign types can be summarized as follows:

- The passive plant uses simple safety systems that are essentially non-active. This is the so-called "walk away safe" design that does not require operator action for an indefinite period of time following an acciden $\mathrm{L}$. Some of the support systems for safety systems that are active in conventional and evolutionary plants can be installed and maintained as nonsafety-related in the passive plant. Examples of such systems include cooling water, HVAC, AC power, and diesel generators. Passive ALWRs are designed to generate power in the $600 \mathrm{MWe}$ range, which is approximately one-half the output that their evolutionary counterparts produce.

- The evolutionary plant uses active safety systems to mitigate accidents. Although these systems are similar to conventional plants, they have additional built-in redundancy and diversity. The evolutionary plant addresses the "walk away safe" concept by using digital, softwaredriven instrumentation and controls to preclude the necessity for operator action for an indefinite time following an accident. Hardwired controls are provided as a backup to allow operators to intervene in the event of computer malfunction.
Even though the passive and evolutionary ALWRs approach plant safety from different perspectives, as noted above, the basic plant designs share many similarities. Each ALWR design type is based on having a staildard plant design for a particular family (e.g., passive $600 \mathrm{MWe}$ PWR), and both ALWR design types have functionally identical structures and equipment. A brief description of some of the major structures and equipment that fall into this category are noted below:

- full-size, zero-leakage, reactor containment buildings

- reactor plant equipment including reactor vessel, steam generators (PWR only) reactor coolant/recirculation pumps, valves, and associated piping

- auxiliary/reactor buildings

- engineered safeguards equipment for reactor inventory control, decay heat removal, and containment heat removal

- diesel generators for onsite power supply

- turbine buildings

- turbine plant equipment including turbine/generator, main condense;, and main feed water and condensate systems

- main and auxiliary electrical switchyards

- $A C$ and DC plant electr ical systems

- cooling towers and associated water handling systems

- fire protection systems

- auxiliary boilers

- storage tanks for condensate and reactor water

- fuel handling and rad waste systems

For the purposes of this report, it is assumed that a passive $600 \mathrm{MWe}$ ALWR plant would be built and operated at SRS. Furthermore, it is assumed that the plant will be a PWR (i. e., Westinghouse AP-600) as more detailed information is available for this plant than any of the other ALWRs. However, most of the general information on cost, fuel loading, etc. should also be applicable to General Electric's 600 MWe Simplified BWR (SBWR) plant.

The initial plant would, most likely, have an initial fuel load that consists of $2 / 3$-core slightly enriched uranium fuel assemblies and 1/3-core MOX fuel assemblies (in keeping with past MOX fuel experience). A typical PWR requires $1 / 3$ of the core to be replaced with freshly reloaded fuel each time the reactor is refueled after the initial cycle of operation. Section 3.2 notes that a $600 \mathrm{MWe}$ plutoniumburning PWR, operating at $75 \%$ availability, would require a 17.9 MT reload batch of MOX fuel per year if refueling were done each year. Although plant economics typically favor a longer fuel cycle such as 18 months, the amount of fuel reloaded each cycle can be expressed in terms of an annual consumption rate. For an AP-600 plant, operating at 
$80 \%$ availability ${ }^{10}$, the reload batch would be a factor of 1.07 higher than the plant discussed in Section 3.2 and the consumption rate would be approximately 19.1 MT of MOX per year. The discharge batch fuel from each cycle's refueling (i.e., 19.1 MT MOX) would be stored underwater in a spent fuel pool, until assembly decay heat became low enough to allow long-term dry storage of the fuel.

The AP-600 is designed to have a gross electrical output of 630 MWe. ${ }^{9}$ Using a cost estimate of $\$ 1,765 / \mathrm{kWe}^{10}$, the completed cost of the AP- 600 plant is expected to be $\$ 1,112$ million in 1990 dollars. The following is a breakdown of the different cost elements.

\section{$1990 \$ / \mathrm{kWe}$}

$\begin{array}{lr}\text { Vendor's Overnight Cost } & 1,370 \\ \text { Owner's Cost } & 156 \\ \text { First-Of-A-Kind Engineering } & 41 \\ \text { Interest During Construction } & 198 \\ \text { Total 1990 \$/kWe Completed Cost } & 1,765\end{array}$

[* Based on plant beirg built "overnight"; includes contingencies but assumes no significant time delay in construction]

The AP-600 reactor, among others, was recently reviewed in Reference 20. Vendor's overnight costs were estimated by EPRI and reported to be $\$ 1,475 / \mathrm{kWe}$ (in 1989 dollars). This is sufficiently close to the above Westinghouse estimate $(\$ 1,370 / \mathrm{kWe}$ in 1990 dollars) as to lend it credibility. However, we have not attempted to estimate the impact of DOE orders on the price of the AP-600. This reactor was designed to coniorm to NRC standards. What more would be required by DOE orders is uncertain.

Assuming a 35-MWe station service load for equipment essential to keeping the plant running, the net electrical output available for use locally or on the grid is $595 \mathrm{MWe}$. With an availability factor of $80 \%$, the plant would generate $4.17 \times 10^{6} \mathrm{MWh}$ of usable power per year of operation. This is based on $595 \mathrm{MWe}$ being generated during $80 \%$ of the 8,760 effective hours/year that the plant is expected to be on line at full power. Reference 9 notes that the average U.S. cnd-use price paid for elcctricity is $6.69 \mathrm{~d} / \mathrm{kWh}$ $(\$ 66.90 / \mathrm{MWh})$, which means that the annual output from the plant has a value approaching $\$ 280$ million. If just a fraction of this output were sold offsite, it might only be worth $\$ 32.50 / \mathrm{MWh}$, which is the rate currently paid to co-generators of small blocks of power (see Appendix C). However, if the entire plant output of $595 \mathrm{MWe}$ were sold on the grid, the prevailing bulk power sales rate might be in the range of $\$ 52.50 / \mathrm{MWh}$.

Reference 10 gives costs of $0.615 \notin / \mathrm{kWh}$ for fuel and $0.1 \mathrm{c} / \mathrm{kWh}$ for decommissioning in 1990 dollars. Reference 11 shows fixed O\&M costs of $\$ 60 / \mathrm{kWe}$ per year and variable O\&M costs of $0.6 \mathrm{mills} / \mathrm{kWh}$, also in 1990 dollars. Based on the plant generating $4.17 \times 10^{6} \mathrm{MWh}$ of usable power per year, these O\&M costs convert to $1.5 \notin / \mathrm{kWh}$. Adding all of the above costs, converting the total to $\$ / \mathrm{MWh}$, and subtracting the result from the co-generation and bulk power sales rates, yields return rates of $\$ 10.35 / \mathrm{MWh}$ and $\$ 30.35 / \mathrm{MWh}$, depending on the fraction of power output sold.

Summarizing the cost information presented thus far, the AP-600 demonstration plant is expected to have a completed cost of $\$ 1,112$ million and net rate of return from electricity sales that is between $\$ 10$ and $\$ 30$ per MWh, all in 1990 dollars. These values have been developed specifically for the AP-600 design plant. However, they should generally be in the range of values for other $600-\mathrm{MWe}$ passive design plants such as the SBWR. Table 4.1 summarizes the above information for a single AP-600 and includes similar information for multiple AP-600s as well as a 1200 MWe evolutionary plant.

\subsubsection{Spent Fuel Management at SRS Without Reprocessing}

Mixed oxide fuel discharged from LWR operation for disposal without reprocessing would be managed using procedures analogous to those for commercial reactor fuels. ${ }^{12}$ The zircaloy-clad $\mathrm{PuO}_{2}-\mathrm{UO}_{2}$ fuel assembled into PWR rod bundles typically 8-1/2-inch square cross section and $12-1 / 2 \mathrm{ft}$ length, would be stored underwater in the reactor pool for a time (assumed about five years) necessary to allow cooling to acceptable heat outputs. The assemblies would then be placed into dry storage until shipment to a geologic National Waste Repository. A flow diagram for this process sequence is shown in Figure 4.4.

The dry storage facility would be one of two types, (1) an underground air-cooled concrete-shielded vault similar to that provided for interim storage of DWPF glass waste canisters $^{13}$, or (2) an above ground unit utilizing concrete storage casks similar in concept to that projected for the Monitored Retrievable Storage facility for commercial spent fuels. ${ }^{12}$ In either case, auxiliary capability would be provided to receive and unload fuel transport casks and to transfer the spent fucl to the Repository. Because no provisions for disposal of the MOX fuel are included in the 
Table 4.1. Comparison of Passive and Evolutionary Plant Output and Costs

\begin{tabular}{|c|c|c|c|}
\hline & \multicolumn{2}{|c|}{ Passive Design } & \multirow{2}{*}{$\begin{array}{c}\text { Evolutionary } \\
\text { Design 1200MWe }\end{array}$} \\
\hline & Single AP-600 & Twin AP-600s & \\
\hline Gross Output, MWe & 630 & 1260 & 1200 \\
\hline Station Service, MWe & 35 & 70 & 60 \\
\hline Net Output, MWe & 595 & 1190 & 1140 \\
\hline Availability, \% & 80 & 80 & 75 \\
\hline Net Output, MWh x $10^{6} /$ year & 4.17 & 8.34 & 7.49 \\
\hline 1990 \$/kW Completed Cost & 1,765 & 1,608 & 1,634 \\
\hline Completed Cost, 1990 \$M & 1,112 & 2,026 & 1,961 \\
\hline Fixed O\&M, 1990 \$k/MWe & 60 & 51 & $55^{1}$ \\
\hline Variable O\&M, 1990 \$k/MWh & 6 & 5 & 5.50 \\
\hline Fuel Cost, 1990\$/MWh & 6.15 & 6.15 & 7.01 \\
\hline Decom. Cost, 1990\$/MWh & 1.00 & 1.00 & 1.00 \\
\hline Avg. Co-gen. Rate, $1990 \$ / M W h$ & 32.50 & 32.50 & 32.50 \\
\hline Avg. Bulk Power Rate, $1990 \$ / M W h$ & 52.50 & 52.50 & 52.50 \\
\hline
\end{tabular}

$\overline{{ }^{\circ} O \& M}$ cost based on average of single and twin AP-600s.

first (Yucca Mountain) Repository and construction of a second Repository would be required, the capacity of the dry storage facility would need to be sufficient to accommodate a total 40-year output of the LWR operation.

Projected quantities of spent fuel processed through interim storage and final disposal are based on a $600 \mathrm{MWe}(1800$ MWt) LWR design, with fuel throughputs of about 17 MTHM per year. For PWR assemblies containing 0.46 MTHM $^{14}$, about 37 assemblies per year would be produced for disposal, to be packaged typically four assemblies per repository container (1.84 MTHM) within nine assembly packages. This approximates the projected spent fuel generation of eight packages per year, based on 'in assumed generation rate of one package per $0.5 \times 10^{6} \mathrm{MWh}$ for an annual reactor output $4 \times 10^{6} \mathrm{MWh}_{\mathrm{c}}$ at $80 \%$ utilization. ${ }^{15,16}$

Costs of disposal without reprocessing are projected for interim onsite storage of the spent fuel and for offsite transport and final disposition in the Repository. Provision of a dry storage facility with capacity for 1500 fuel assemblies (690 MTHM) covering a 40-year reactor life time is projected to cost about $\$ 60$ million in capital and preoperational expenditures, and about $\$ 5$ million/year in operational costs. The capital costs were based on a Monitored Retrievable Storage-type facility with storage capacity 15,000 MTHM costing about $\$ 375$ million (1990 $\$$ ) scaled in accord with the following factors:

$$
\text { Capital Cost }=\left(\frac{690 \mathrm{MTHM}}{15,000 \mathrm{MTHM}}\right)^{0.6} * \$ 375 \mathrm{M} \cong \$ 60 \mathrm{M}
$$

This cost is about equal to the cost of underground storage vaults for DWPF glass waste canisters (2500 canisters/ vault), in satisfactory agreement considering differences in spacing required for the spent fuel storage. Operating costs somewhat greater than for other fuel-types were projected to accommodate potential health protection and security requirements for the plutonium-containing spent fuel.

Cost assessments to cover Repository disposal depend generally on the numbers of spent fuel packages handled. The costs of commercial spent fuel disposal are equivalent to about $\$ 500,000$ per package ${ }^{16,17}$, totaling, for the nine packages per year produced by LWR operation at SRS, about $\$ 4$ million per year. This projection is in agreement with that calculated from the utility waste disposal fee assessed at 1 mill per $\mathrm{KWhe}$ ( $\$ 1$ per $M W h_{0}$ ) of nuclear electricity sold (e.g., $4 \times 10^{6} \mathrm{MWH} / \mathrm{yr} \times \$ 1.00=\$ 4 \mathrm{M} / \mathrm{yr}$ ). Offsite transportation costs are included in this charge.

It is assumed in this assessment that disposal of the low concentration plutonium-containing MOX fuels discharged from an SRS LWR reactor would be handled and stored at 


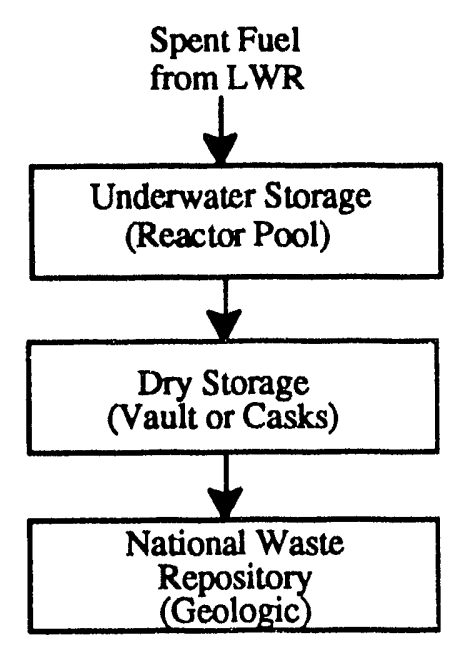

Figure 4.4 LWR Spent Fuel Management Without Reprocessing

the Repository using essentially the same procedures as for low-enriched uranium fuels. Qualification of the MOX fuels for such Repository disposal would be required at an incremental cost projected at about $\$ 50$ million. This qualification cost estimate is considerably smaller than indicated for a new waste form. ${ }^{18}$

\subsection{Phase 2 - Using MOX Fuel in Utility LWRs}

Following demonstration of the plutonium-burning reactor concept, the potential exists to irradiate larger amounts of fuels in utility reactors that are in close proximity to SRS.

\subsubsection{Expanded MOX Fuel Plant}

The 60-70 MTHM/year fuel plant could be used to make fuel for the offsite utility reactors. To denature $50 \mathrm{MT}$ in 40 years, the output required is a maximum of 69 MTHM per year. By operating the facility described in Section 4.1.1 on a three-shift basis, the required fuel can be made.

The flow diagram for the process concept is shown in Figure 4.5. Depleted uranium and plutonium metal is converted to oxides. The powders are blended, granulated, pelletized, sintered, dimensionally sized, and loaded into fuel tubes. The fuel tubes are then fabricated into fuel assemblies. Fuel assemblies are shipped to the onsite initial LWR and to offsite utility LWRs.

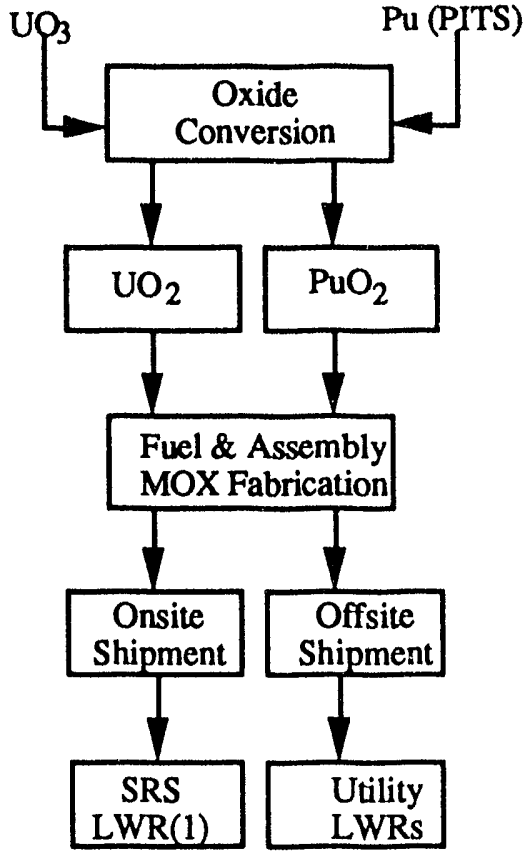

Figure 4.5. Expanded MOX Facility to Supply Onsite Demonstration LWR and Up to Three Offsite Utility LWRs

\section{Cost Estimate}

The cost for a $\sim 60-70$ MTHM/year "greenfield" complex was estimated to be $\$ 680$ million. This plant is expected to produce the fuel required for the two to three $600 \mathrm{MWe}$ reactors by operating on a three-shift basis. By operating with three shifts, the facility operating cost is expected to be about $\$ 60$ million/yr based on 1991 300-Area operating costs.

\subsubsection{Utility LWR Use of Plutonium}

Phase 2 of this strategy involves utility participation to eliminate excess plutonium from the U.S. weapons stockpile. After an ALWR is demonstrated as a viable means of burning plutonium in a MOX-type fuel at SRS, utility LWRs could presumably be licensed to do the same thing. In the mid-1970s, the NRC stated its provisional views on licensing MOX fuel for wide-scale use in utility-owned LWRs. A summary of these views is provided below:

- The subject of wide-scale use of MOX fuel in LWR fuel cycles will require a full assessment of safeguards issues before the Commission makes any decision. 
- An environmental impact statement (EIS), including safety, environmental, and safeguards maters, on the wide-scale use of MOX must be prepared by the NRC staff.

- Public, legislative-type hearings need to be held on the final EIS and the proposed rules related to wide-scale use, prior to the Commission rendering a decision. These hearings may be followed by adjudicatory hearings on particular issues should the need arise.

At the time these views were written, wide-scale use of MOX was defined to include operating reprocessing facilities and fuel element fabrication plants as well as operating LWRs with MOX fuel. To address the continued use of MOX fuel in LWRs for experimental purposes, the NRC noted that such use would necessarily fall short of wide-scale use, and amendments to operating licenses would be issued without going through a full scope process (e.g., EIS, public hearings). In fact, no limits were placed on the number of LWRs that would be allowed to burn MOX fuel. However, the NRC noted that MOX fuel fabrication capacity was also limited at the time.

An assessment of what is required to amend the operating license of an LWR to use MOX fuel is difficult to make. After the NRC wrote its views on MOX fuel in the mid-1970s, the U.S. policy changed to defer indefinitely reprocessing commercial LWR fuel. Although that decision was overturned in the 1980s, the price of uranium enrichment dropped to where using plutonium in a MOX fuel was not economically favorable. In addition, the NRC has not issued any additional notices on licensing MOX fuel for LWRs since 1975.

A best estimate of how utility-owned $L$ WRs might request a license to burn weapons-grade plutonium in MOX fuel assumes that any LWR that uses MOX fuel is within several hours travel time from the SRS MOX fuel fabrication plant. The proximity restriction limits exposure to any attempt to divert the weapons-based fucl for terrorist purposes. Limiting the distance between the fuel plant and the LWR user makes the issue of safeguards easier to address. LWRs that meet the distance requirement from SRS are in the range of $700 \mathrm{MWe}$ (Robinson) to $1150 \mathrm{MWe}$ (Vogtle) net power.

Aside from the safeguard issues, it is assumed that an EIS has to be prepared as a pre-requisite to any license amendment. The EIS would be followed by a series of public hearings at locations surrounding the LWR that requests the amendment. Additional hearings would likely be held in Washington, DC, involving the NRC, DOE, and the Atomic Safety \& Licensing Board. Preparing an EIS and attending various hearings would cost the licensee request- ing an amendment considerable time and expense. And, furthermore, the amendment may not even be granted after going through the request process.

Utilities are in business to make money for their investors. Therefore, the first step to convince a utility to go through the process to allow them to burn MOX fuel in their LWR is to offer an incentive. A logical incentive is to offer MOX fuel at significantly reduced cost (compared to U-235) or a phased-in cost approach whereby the fuel is cost-free until the utility recovers its expenses from the license amendment process. At that point, the fuel might be sold based on its fabrication cost alone. To explain the economics of such an approach, the following example is provided.

Based on inserting a $1 / 3$-core reload each refueling, the steady-state fuel cost is $\$ 7.01 / \mathrm{MWh}_{0}$ (1990 dollars), which includes a $\$ 1.00 / \mathrm{MWh}_{0}$ waste disposal fee and makes the actual fuel cost $\$ 6.01 / \mathrm{MWh}$ for a conventional $L W R^{10}$. As noted above, the range of net power output from plants that might be plutonium burners is 700 to $1150 \mathrm{MWe}$. Using an industry average availability of $70 \%$, the annual value of fuel for the smaller plant is:

Fuel value $=(.70)(8760 \mathrm{hr} /$ year $)(700 \mathrm{MWe})(\$ 6.01 / \mathrm{MWh})$ = \$26 million per year in 1990 \$

Similarly, the annual value of fuel for the larger plant is:

$$
\begin{aligned}
\text { Fuel value } & =(.70)(8760 \mathrm{hr} / \text { year })(1150 \mathrm{MWe})(\$ 6.01 / \mathrm{MWh}) \\
& =\$ 42 \text { million per year in } 1990 \$
\end{aligned}
$$

Aside from any risks associated with obtaining a license amendment, the economics of the weapons-based fuel offers a strong incentive for a utility to pursue a course to license its LWR(s) to burn MOX. The utilities most likely to pursue such an amendment process operate large multiple units. The incentive would be greater than at a utility operating one small unit. In addition to costs incurred during the license amendment process, a utility that successfully obtained an amendment would have to substantially upgrade its guard force to alleviate NRC safeguards concerns. This aspect strengthens the argument that a utility with multiple LWRs on a site would more likely get involved with MOX fuel than a utility with one unit on a site.

In regards to MOX fuel usage, the Section 3.2 calculation that a $600 \mathrm{MWe}$ LWR operating at $75 \%$ availability will require $17.9 \mathrm{MT}$ of MOX fuel per year can be used to obtain estimates for the example plants described above. A 700 MWe LWR operating at $70 \%$ availability will use 
$(.70 / .75)(700 \mathrm{MWe} / 600 \mathrm{MWe})(17.9 \mathrm{MT}$ of MOX) or 19.5 MT of MOX fuel per year. Using a similar scale-up approach, the $115 \mathrm{C} \mathrm{MWe} \mathrm{LWR}$ will use $32 \mathrm{MT}$ of MOX fuel per year.

Summarizing the above information, a utility-owned LWR is expected to use between $19.5 \mathrm{MT}(700 \mathrm{MWe}$ unit $)$ and 32 MT (1150 MWe unit) of MOX fuel per year, even though refuelings may be conducted on an 18-month cycle. The value of this fuel is estimated at $\$ 26$ million per year for a $700 \mathrm{MWe}$ plant and $\$ 42$ million per year for an $1150 \mathrm{MWe}$ plant, all in 1990 dollars. With the cost of the plutoniurn already paid for by the weapons program, the only real cost associated with this fuel is in fabricating LWR fuel assemblies.

\subsubsection{Spent Fuel Management at Utilities}

MOX fuel storage and disposal of discharged fuel from commercial power reactors can be handled generally as described for a demonstration reactor at SRS. Commercial spent fuel management involves the same operations on which the site direct disposal scenario was based, namely interim under-water storage in reactor pools, supplemented by longer term dry storage pending final disposition in the National Waste Repository. ${ }^{12}$ The dry storage facilities include, besides those under development for local use at the reactor site, the Monitored Retrievable Storage facility proposed for handling and storage of the commercial spent fuel delivered to the federal government prior to iepository availability. Funding of the capital and operating expenses of the Monitored Retrievable Storage facility are included in . the waste disposal fee collected from the commercial uúlities.

Spent fuel generation in commercial reactors potentially using MOX fuel is assumed directly dependent on the MTHM utilized, in accord with considerations of Section 4.1.3. For $600 \mathrm{MWe}$ reactors, each $17 \mathrm{MT} H \mathrm{H}$ discharged per year would be contained in about 37 PWR-type assemblies comprising 9 spent fucl packages for repository disposal. A three-reactor complex, for example, would generate about 110 assemblies equivalent to 28 repository packages. Assessed at $\$ 500,000$ per package, the repository costs for disposal of these spent fuel packages would be about $\$ 14$ million/year of reactor operation.

Again, qualification of MOX fuel for repository disposal would incur an incremental cost up to $\$ 50$ million independent of the quantity of fuel produced.

\section{References}

1. H. Bairiol. "Laying the Foundations for Plutonium Recycle in Light Water Reactors". Nuclear Engineering international (January 1984).

2. 'PNC's Fully Automated MOX Plant Starts Operation". Nuclear Engineering International 33(403): 18 (1988).

3. "Siemens says Russian Copy of SBH Could be Built in Three Years". Nuclear Fuel (June 22, 1992).

4. Design Integration Study - Spent LWR Fuel Recycle Complex, Savannah River Laboratory Report DPCFP-78-121, Savannah River Site, Aiken, SC 29808.

5. H. Bairiot. and C. Vandenberg. Use of MOX Fuels, Nuclear Fuel Cycle in the 1990s and Beyond the Century: Some Trends and Foreseeable Problems. Technical Reports Series No. 305, International Atomic Encrgy Agency, Vienna, Austria, pp 65-95 (1989).

6. J. D. Duane. Mixed Oxide Demonstration Fuel Fabrication Facility, Preliminary Study. RN\# NMP. SPA-920229 (July 1992).

7. R. L. Frontroth. 300-M Area Strategic Plan (U). US DOE Report WSRC-RP-91-661, Savannah River Site, Aiken, SC 29808 (July 1991).

8. Telephone Conversations with Randy Erskine of the South Carolina Public Service Commission on Electric Rates for Co-Generators, June 5, 1992, and July 8, 1992.

9. Energy Information Administration, Annual Energy Outlook 1992.

10. Westinghouse Electric Corporation (WEC). The Westinghouse AP-600. (Revised December, 1991).

11. U.S. Council for Energy Awareness. Advanced Design Nuclear Power Plants Competitive Economical Electricity (June 1990).

12. Analyses of the Total System Life Cycle Cost for the Civilian Radioactive Waste Management Program. DOE/RW-0236, U.S. Department of Energy, Office of Civilian Radioactive Waste Management (May 1989).

13. Survey and Assessment of Radioactive Waste Management Facilities in the United States. "Section 2.5 Air-Cooled Vault Storage Facilities", DP-MS-86-37, Bechtel National, Inc. (June 1986).

14. Design Integration Study, Spent LWR Fuel Recycle Complex. DP-CFP-78-121, E.I. du Pont de Nemours and Co., Savannah River Laboratory (November 1978) pp 6-34.

15. Perspective on Methods to Calculate a Fee for Disposul of Defense High-Level Waste in (Civilian/Defense) Repositories. DOE/RL-86-10, U.S. Depart- 
fense) Repositories. DOE/RL-86-10, U.S. Department of Energy, Defense High-Level Waste Technology Program Office, Richland, WA (1986).

16. W.R. McDonell and P. L. Gray. Impact of Repository Fee on Defense Waste Disposal Costs. DPST-89-376 (March 1989).

17. Nuclear Waste Fund Fee Adequacy: An Assessment. DOE/RW-0219P, U.S. Department of Energy, Office of Civilian Waste Management (November 1990).
18. N.A. Chipman. Visit with Yucca Mountain Site Characterization Project Office Personnel. NAC-8-91 (Attachment 4,p 6; Attachment 5;p 4) (May 6, 1991).

19. "BNFL to Decide this Year Whether to Build MOX Facility". Nuclear Fuel (September 14, 1992).

20. Committee on Future Nuclear Power Development. Nuclear Power, Technical and Institutional Options for the Future. National Research Council. National Academy Press, Washington, DC (1992). 


\section{Strategy 2 - Energy Park Use of Plutonium Fuel}

\subsection{Initial LWR at SRS}

The object of Strategy 2 is to create a government-owned energy complex that would eliminate excess weapons-grade plutonium by denaturing it in MOX fuel, using commercial light water reactor (LWR) technology. The initial plant would be used to prove the technology and generate electric power at the same time. Phase 1 of this strategy involves constructing and operating a MOX fuel fabrication facility and LWR at SRS to demonstrate the plutonium fuel burning concept. As envisioned, the plutonium fuel burner would be an advanced light water reactor (ALWR), either a passive design plant in the $600 \mathrm{MWe}$ range or an evolutionary design plant in the $1200 \mathrm{MWe}$ range.

Note that Section 4.1.2 provides a much more complete description of the initial LWR; however, the cost information is summarized here for convenience. For a single plant in the 600-MWe range (passive design ALWR), the completed cost is expected to be $\$ 1,112$ million and electric power sales are estimated to produce a net rate of return in the range of $\$ 10$ to $\$ 30$ per $M W h$, all in 1990 dollars. The initial plant was assumed to be an AP- 600 only because very little information was available for other plants such as the passive SBWR and the evolutionary designs.

\subsection{Additional Reactors at SRS}

Phase 2 of this strategy involves constructing and operating additional advanced reactors, beyond the initial plant, to eliminate all excess plutonium in the weapons stockpile. These units could be additional ALWRs or, perhaps, other advanced reactor concepts such as the advanced liquid metal reactor or the MHTGR if these concepts become attractive enough to compete both technically and economically with ALWRs. For the purpose of the cost analysis, the additional reactors are assumed to be ALWRs because these designs are sufficiently developed to have confidence in the cost and schedule. As the other advanced concepts progress through the design certification process, it will be possible to evaluate their viability to include the energy park.

As envisioned, these additional plants would be grouped within a government-owned energy complex. The power output from this complex could be distributed to utilities in the southeast U.S. by "wheeling" the power over the grid and selling it off at pre'sailing bulk power rates. Table 4.1 summarizes and compares the passive and evolutionary ALWR plant outputs and costs.

Appendix $\mathrm{C}$ derives an average rate of $3.25 \mathrm{c} / \mathrm{kWh}$ that area utilities are willing to pay to small co-generators (i.e., generation is typically less than $1 \mathrm{MWe}$ ). Most of these co-generators produce power for their own use and sell the excess back to the utilities. In contrast, the governmentowned energy complex would produce power in the several thousand MWe range and could provide a substitute for new plants that utilities will have to build to meet future load growth. Florida and Virginia-Carolina subregions of the southeast U.S. are expecting to increase generation capacity by approximately $13,000 \mathrm{MWe}$ from 1990 to $2001 .^{1}$ This projected increase does not include any new generation to replace existing older plants that might have to be retired during that time period.

If an energy complex were to be built by the government, the amount of power it could produce would save utilities the expense of licensing, constructing, and operating new plants. The value of power produced by the complex would most likely be worth more than the current rate of $3.25 \notin / \mathrm{kWh}$ that area utilities pay to small co-generators, who are not structured to provide significant blocks of power to meet increased load. A best estimate for selling bulk power over the grid is in the range of $5 \notin / \mathrm{kWh}$ to $5.5 \mathrm{c} / \mathrm{kWh}$, given that the average end-use price in the U.S. is $6.69 \mathrm{~d} / \mathrm{kWh}$. Based on anticipated power needs for the southeast U.S., it seems reasonable to expect that plutonium-burning LWRs in the complex would be able to more than offset their cost of construction and operation.

For the $600 \mathrm{MWe}$ passive plant, the completed cost for more units decreases from $\$ 1,112$ million to $\$ 977$ million per individual unit. However, the $1200 \mathrm{MWe}$ evolutionary plant shows virtually no decrease. ${ }^{2}$ The completed cost per unit for multiple plants built on the same site should decrease even more compared to the above estimates. This reduction would result from shared facilities and economies realized by constructing identical units on the same site.

Section 4.1.2 shows a fuel usage rate of 19.1 MT of MOX per year for a single $600 \mathrm{MWe}$ passive ALWR. This is based on scaling up the fuel usage estimate from Section 3.2 to account for greater plant availability. Usage estimates for the $1200 \mathrm{MWe}$ evolutionary plant are scaled up in a similar 
fashion to 35.8 MT of MOX fuel per year for each plant of this size.

\section{References}

1. North American Electric Reliability Council. Electricity Supply and Demand 1991-2000. (July 1991).

2. Westinghouse Electric Corporation (WEC). The Westinghouse AP-600. Revised (December 1991). 


\section{Summarized Costs for Plutonium Denaturing Strategies}

\subsection{Individual Component Costs}

Table 6.1 summarizes the cost data given in the previous sections of the report. Reactor-related costs given in Sections 4 and 5 have been escalated from 1990 dollars to 1992 dollars, assuming an escalation rate of $4.5 \%$ per year. In some cases, values were rounded for convenience and to reflect uncertainties. The costs and revenues are those which would be borne and received by DOE.

\subsection{Life Cycle Costs}

A simple life cycle cost analysis is performed for Strategy 2 using the costs given in Table 6.1. A summary of the results is given in Table 6.2.

The largest uncertainty is associated with the cost of the MOX facility to be constructed at SRS. We have elected to use the capital cost estimate of $\$ 200$ million for Building 235-F.

The analysis was done assuming a 6-year construction period followed by a 40 -year operating period. For Case 5.2 , costs are displaced by 10 years relative to Case 5.1 for a total period of 50 years.

One year's operating costs were included during the last year of construction to account for pre-startup operating costs.

The net present value (NPV) is given for discount rates of $0 \%$ (undiscounted), $5 \%$, and $10 \%$. The latter is the rate specified in OMB Circular A-94 for analyzing government projects.

The undiscounted cost is the sum of the electricity sales less the sum of the capital and operating costs over the lifetime of the project.

Discounting is a method for evaluating the measurable costs and/or benefits of programs and projects when they are distributed over time. It takes into account the time value of money and some measure of the risk involved. The present value (PV) is defined as the value today of a sum of money in the future, a future value (FV), and is expressed as:

$$
\mathrm{PV}=\mathrm{FV} /(1+\mathrm{d})^{\mathrm{n}}
$$

where: $d$ is the discount rate

$$
\mathrm{n} \text { is the number of years in the future. }
$$

As shown on Table 6.2, the weapons-grade plutonium can be denatured in the SRS Energy Park (Strategy 2) at a net cost of $\sim \$ 700$ million (10\% discount rate) or a net profit of $\$ 1.1$ billion (5\% discount rate). These results show that the excess plutonium stockpile can be denatured with essentially zero net cost if Strategy 2 is followed. If the proliferation concerns of Strategy 1 can be overcome, the potential for net profit could be even larger. 
Table 6.1. DOE Costs and Revenue

Phase 1

Phase 2

(Incremental to Phase 1)

\begin{tabular}{|c|c|c|c|}
\hline & Demonstration & $\begin{array}{c}\text { Additional Reactors } \\
\text { Energy Park } \\
\end{array}$ & $\begin{array}{c}\text { Use of } \\
\text { Utility Reactors } \\
\end{array}$ \\
\hline Number of Reactors & 1 & 2 & a \\
\hline \multicolumn{4}{|l|}{ Capital and other Pre-startup } \\
\hline \multicolumn{4}{|l|}{ MOX Plant: } \\
\hline Existing SRS Building & 200 & 0 & 0 \\
\hline Greenfield Facility & 680 & 0 & 0 \\
\hline Reactors & 1,200 & 2,200 & b \\
\hline Initial Core $(2 / 3$ LEU) & 55 & 110 & b \\
\hline Spent Fuel Storage & 70 & 40 & b \\
\hline Spent Fuel Disposal & 60 & 0 & b \\
\hline \multicolumn{4}{|l|}{ Operating } \\
\hline MOX Plant: Existing SRS Building & 30 & 30 & 30 \\
\hline Reactors & 95 & 100 & b \\
\hline Spent Fuel Storage & 5 & 5 & b \\
\hline Spent Fuel Disposal & 5 & 10 & $\mathrm{~b}$ \\
\hline \multicolumn{4}{|l|}{ Revenue } \\
\hline Electricity & & & c \\
\hline Amount, millions $\mathrm{MWh} / \mathrm{yr}$ & 4.2 & 8.4 & \\
\hline Sale Price, \$/MWh & 57 & 57 & \\
\hline Annual Revenue, Millions $\$ / y \mathrm{r}$ & 240 & 480 & \\
\hline Fuel Sales to Utilities & & & $\mathrm{d}$ \\
\hline
\end{tabular}

a - The fuel could be irradiated in any number of reactors.

b - The costs to DOE would be the incremerital costs of licensing, etc.

c - The utility would receive all revenue as before.

d - The payment for the fuel would depend on incentive needed to attract participation. 
Table 6.2. Life Cycle Costs

(40-year operating life, no D\&D costs)

Basis:

\begin{tabular}{|l|c|c|}
\hline \multicolumn{1}{|c|}{ Strategy } & 5.1 & $5.1 \& 5.2$ \\
\hline MOX Plant & SRS Mod. & SRS Mod. \\
Initial Core & $2 / 3$ LEU & $2 / 3$ LEU \\
Reactor & 1 at SRS & 3 at SRS \\
Spent Fuel Storage & at SRS & at SRS \\
Spent Fuel Disposal & Repository & Repository \\
Electricity Sales, \$/MWh & 57 & 57 \\
\hline
\end{tabular}

\begin{tabular}{|l|c|c|}
\hline \multicolumn{1}{|c|}{ Costs and Income } & $\mathbf{5 . 1}$ & $\mathbf{5 . 1} \& \mathbf{5 . 2}$ \\
\hline Capital and Other One-time & 1,600 & 3,900 \\
Operating & 5,500 & 11,500 \\
Electricity Sales & 9,600 & 28,800 \\
\hline
\end{tabular}

\begin{tabular}{|l|r|r|}
\hline \multicolumn{1}{|c|}{ Total Life Cycle, Net Present Value * } & $\mathbf{5 . 1}$ & $\mathbf{5 . 1} \& \mathbf{5 . 2}$ \\
\hline Undiscounted & 2,500 & 13,400 \\
5\% Discount Rate & -100 & 1,100 \\
10\% Discount Rate & -700 & -700 \\
& & \\
*Positive values indicate that income exceeds expenses & & \\
\hline
\end{tabular}




\section{Recommendations}

The proposed use of advanced LWR technology with a plutonium fuel cycle provides a reliable and cost-effective option for denaturing the excess weapons-grade plutonium stockpile. Because this concept will also help to advance the nuclear industry through demonstration of evolutionary or passive safe features, it has the potential to attract considerable, broad-based support. It also provides the U.S. government with an opportunity to exercise world leadership in the area of disarmament and the establishment of the terms for peaceful co-existence. Additionally, the concept is optimized if a national policy for reprocessing of nuclear fuels and actinide burning is adopted.

It is recommended that activities be initiated early in FY 93 to enable DOE to make a major systems acquisition of a plutonium-burning ALWR and the supporting facilities by the end of FY 93. Such activities would include:

1. Detailed quantification of the plutonium and an isotopic contents of the stockpile to size the MOX fuel fabrication plant and address radiation dose and criticality issues.

2. Selection of the least-risk, least-cost fuel fabrication flow shect based on an evaluation of alternative processes.

3. Evaluation of MOX fuel fabrication faciliites options, such as, greenfield facilities and/or existing DOE facilities. Development of pre-conceptual designs, cost estimates, and level 1 schedules.

4. Specification of reactor core design (fuel content and fuel assembly dimensions, reactor face map, reactor thermal hydraulics). Specification of the first core and equilibrium fuel cycle. Determination of denaturization rate.

5. Performance of core-dependent safety analyses for the plutonium-burning ALWR and comparison to the previous GESMO analysis and to the safety envelope in ALWR SAR submittals to the NRC.

6. Preparation of a detailed spent fuel disposal plan including life cy: le costs and schedules for a disposition of mixed oxide fuel in a Repository.

7. Estimation of environmental releases for normal and off-normal operations of the plutonium fuel burner facilities.

8. Definition of program-level requirements early in FY 93 to guide the above studies. These requirements would be refined during the year.

9. Preparation of cost estimates and level 1 schedules for the program, and generation of major system acquisition documentation.

It is further recommended that contacts with reactor vendors and utilities be initiated to investigate the interest and level of commitment for a venture of this type. It is envisioned that a project team would involve the three organizations as follows:

\section{Organization}

- Vendor (or group of vendors)

- Utility (or group of utilities)

- DOE

\section{Responsibility}

- Reactor and Balance of Plant Designs

- Electrical Sales Commitment

- Project Management Coordination and overall Project Funding

Of course, the NRC would also need to be closely associated with the project team to assist in coordination of the overall licensing process. Using this approach, it would be possible to involve all interested parties in a coordinated effort to advance the nuclear industry and denature plutonium at the same time. 


\section{Appendix A. Tritium Target Technology}

The target technology necessary to produce tritium under conditions anticipated in a plutonium-burning LWR has been demonstrated on a laboratory scale but not yet on a production scale. This appendix traces the current and projected technologies that could be used for tritium production.

\section{A.1 Heavy Water - Production Reactor Target Technology}

The Savannah River Site, working within the DOE Nuclear Weapons Complex, lias developed, demonstrated, and successfully proven tritium production and extraction processes using low-temperature, aluminum-lithium alloy target technology. However, this technology is not readily extrapolated for use in a power reactor, because corrosion of aluminum alloy cladding limits the cooling water temperature to approximately $200^{\circ} \mathrm{C}$. Even if developments eliminated the corrosion concerns, tritium retention in the target is limited at approximately $400^{\circ} \mathrm{C}$. Morcover, the melting temperature of aluminum alloys $\left(600^{\circ} \mathrm{C}\right.$ to $\left.660^{\circ} \mathrm{C}\right)$ would place significant restrictions on reactor operations because of anticipated response to postulated accidents.

\section{A.2 High Temperature Target Development}

\section{A.2.1 Aluminum Can Technology}

This target, which consists of lithium aluminate pellets encapsulated in an aluminum can, has been used for tritium production in helium-cooled reactors. Tritium extractions for such targets has been accomplished at SRS with limited success. However, this target also suffers from the temperature limits imposed by the melting temperature of aluminum. The temperature restriction is not eliminated, and may even be lowered because of aluminum reactions with surrounding metals if the aluminum can target is further encapsulated in magnesium or stainless steel.

\section{A.2.2 Getter-Barrier and Silicon-Carbide Technologies}

Other high-temperature target technologies currently being developed on laboratory scales include a getter-barrier target and a silicon-carbide encapsulated lithium-aluminate microsphere. The getter-barrier target is a conceptual target proposed for high-temperature, light-water reactors. This target consists of lithium-aluminate pellets and an associated zirconium getter contained in an aluminized stainless steel tube with weld enclosures on both ends. Neither the fabrication of the aluminized tubing nor the irradiation and extraction behavior of the target have been established, except for limited laboratory scale testing. Furthermore, corrosion of the aluminized coating may be a significant problem if that coating is exposed to high-temperature water.

Production scale demonstrations of the silicon carbide encapsulated lithium-aluminate microspheres are also lacking, although, recent work with that target technology has provided promising results. This target was developed for high-temperature, gas-cooled reactors and extrapolation of that technology to a plutonium-burning reactor is not direct. However, the microsphere technology should provide a technique for placing a target material, with high-temperature tritium containing capabilities, inside a stainless steel tubing. This stainless steel tube would contain the very limited quantities of tritium that would be released to the tube if any of the microspheres were fractured during target fabrication. Clearly, the stainless steel microsphere target technology has not been demonstrated, but the potential use of the target in the plutonium-burning reactor will be further established as additional data from the MHTGR target development studies become available.

Tritium extraction for any of the lithium aluminate targets does not provide a direct interface with the existing tritium extraction facilities at SRS. New facilities will be required, but the interface between those facilities and the existing extraction and purification facilities should be readily established. 


\section{Appendix B. Burning Plutonium in Energy Park with Reprocessing and Actinide Burning}

This strategy combines the use of plutonium to fuel several ALWRs in an energy park with reprocessing and actinide burning to maximize the utilization of fissile materials (i.e., plutonium and uranium) as well as to reduce the time requirements for waste containment. The strategy includes three phases:

1. MOX fuel fabrication plant and ALWR

2. Reprocessing and actinide buming facilities

3. Additional advanced reactors to form an energy park

Two primary options are being evaluated for actinide consumption, integral fast reactor (IFR) and a linear accelerator concept, Accelerator Transmutation of Waste (ATW). Either of these options would be app:opriate for this strategy, but for illustrative purposes the IFR has been chosen for this discussion. With simple modifications, the ATW could be easily substituted, and a portion of the power from the energy park would be used to operate the accelerator.

The separated waste streams from irradiated LWR fuel can be divided into two categories; fission products and actinides. Actinides are produced in LWRs through neutron capture reactions. The plutonium isotopes make up a large majority of the actinides produced during irradiation of LWR fuel. it is common to refer to the non-plutonium actinides as "minor actinides", simply because so much less of them is produced. As opposed to the fission products, most of which have half-lives less than 100 years, the actinides have very long half-lives. It is the actinides that are responsible for the 10,000-year decay period for which a National Waste Repository is to be designed. If the actinide isotopes can be converted to short half-life fission products, the demands on the waste repository are gready reduced, because waste would only need to he isolated for several hundred years.

A means of converting the actinides to fission products is to burn them in a reactor. However, a thermal spectrum reactor (water or graphite-moderated) is not conducive to actinide burning because the ratio of neutron capture to fission for the actinides in the thermal energy range favors the capiure event, which simply creates higher actinid 's. In contrast, a fast reactor is ideally suited for the task. As neutron energy increases, the fission to capture ratio increases; in fast reactors, actinide fission is more probable than capture.
Therefore, fast reactors can be used to burn the actinides discharged from LWRs. (Note that while the actinide content of discharged fuel from a plutonium-fueled LWR would be different than that from a conventional LWR, the concept of actinide burning is unchanged).

Although the concept is attractive, preliminary cost estimates are very high. Pigford' has shown that chemical processing to separate elements could multiply the total volume of radioactive wastes, including low-level waste by a factor of 10 , making the economics unfavorable.

In this proposed strategy, spent LWR actinide waste is used to produce fuel elements for the IFR. Fuel will be manufactured and shipped to an onsite IFR for irradiation. After transmutation, the fuel assemblies will be returned for chemical reprocessing, completing the cycle. Figure B.1 shows the SRS fuel cycle for IFR fuel.

\section{B.1 Fuel Fabrication}

The metal fuel for this concept consists of cast U-Pu-MA-Zr alloy where MA represents metal actinides. The expected composition of the alloy about $20 \mathrm{wt} \%$ plutonium, $10 \mathrm{wt} \%$ zirconium, and $10 \mathrm{wt} \%$ actinides with the balance in depleted uranium. Typical IFR fuel elements are expected to be about 0.2 inches in diameter and about $3-1 / 2 \mathrm{ft}$ long and are manufactured by injection casting. Returned plutonium and actinide metals can be burned in a fast ieactor without breeding additional plutonium. Test assemblies of U-Pu-Zr metallic fuel have demonstrated excellent steady state performance during irradiation. ${ }^{2}$ However, the effect on cladding reactions from relatively high concentrations of metal actinides has not been evaluated completely.

Fuel fabrication, shown in Figure B.2, will be done remotely in a hot cell because of gamma-emitting actinide elements. Uranium and actinide elements may be separated from ALWR fuel rods and converted to metals by chemical or pyroprocessing techniques. The depleted uranium, plutonium, and actinide metal will be alloyed with zirconium in a graphite crucible in a vacuum furnace. The molten alloy is injection cast under argon pressure into quartz tubes. After cooling, the quartz tube is broken, and the pins are ready for assembly into fuels rods. The cladding material may be either austenitic or ferritic stainless steel. Each casting 
produces up to 100 pins that are about 14 inches long. Figure B. 3 is a schematic diagram of the casting operation.

The IFR fabrication facility will be built adjacent to the MOX fuel plant. Major additions to this building will include the hot cell to contain the injection casting and fuel assembly operations.

Preliminary capital cost estimates for an IFR fuel facility (to support a $1400 \mathrm{MW}$ generating capacity) using the pyroprocessing technique and injection casting is $\sim \$ 97$ million. ${ }^{3}$ This estimate includes construction costs of the building, engineering and construction services, and procuring and installing equipment for reprocessing, fabrication, waste packaging, and interim storage. Operating and maintenance costs are estimated to be about $\$ 90$ million per year. ${ }^{3}$ These costs include process and support personnel, process consumables, utilities, and allowances for spare parts and equipment. As stated below, the reprocessing scheme envisioned in this appendix is aqueous rather than pyrochemical. No attempt has been made to strip out the reprocessing costs.

\section{B.2 Reprocessing Plant}

A reprocessing plant capable of recovering the actinides from three LWRs (600 MWe) and one IFR must have a capacity to process about 75 metric tons per year of heavy metals (MTHM/yr) or $300 \mathrm{~kg}$ of heavy metals per day. The concept for reprocessing is to partition the long-lived actinides from the fission products to a level so low that the fission product waste needs to be isolated from the environment for $<1000$ years. At this time, the design basis plant would use aqueous technology that exists or is developed enough to ensure successful operation. Although pyrochemical technology is attractive because of the smaller plant size, reduced effects from high radiation, and smaller operating staff, the technology is not sufficiently developed to ensure that long-lived actinide isotopes can be efficiently removed to allow the wastes to decay in $<1000$ years. In addition, a waste form for pyrochemical processes must be developed and certified to be acceptable for longterm storage in a repository. If design of the reprocessing facility does not begin within the next 10 years, pyrochemical processes may have been developed enough to be the preferred technology.

Figure B.4 shows the flow of material through the reprocessing plant. Spent ALWR fuel would be stored in a basin for one to five years prior to transfer to the reprocessing facility. The assemblies would be sheared to expose the oxide fuel before dissolution in nitric acid. Recovery and purification of uranium and plutonium would use the proven PUREX solvent extraction lechnology. Plutonium and uranium would be coextracted and separated in a first cycle of solvent extraction in a combination of centrifugal contactors and mixer-settlers to maximize decontamination from fission products. The uranium solution from the first cycle would be concentrated by evaporation and purified by

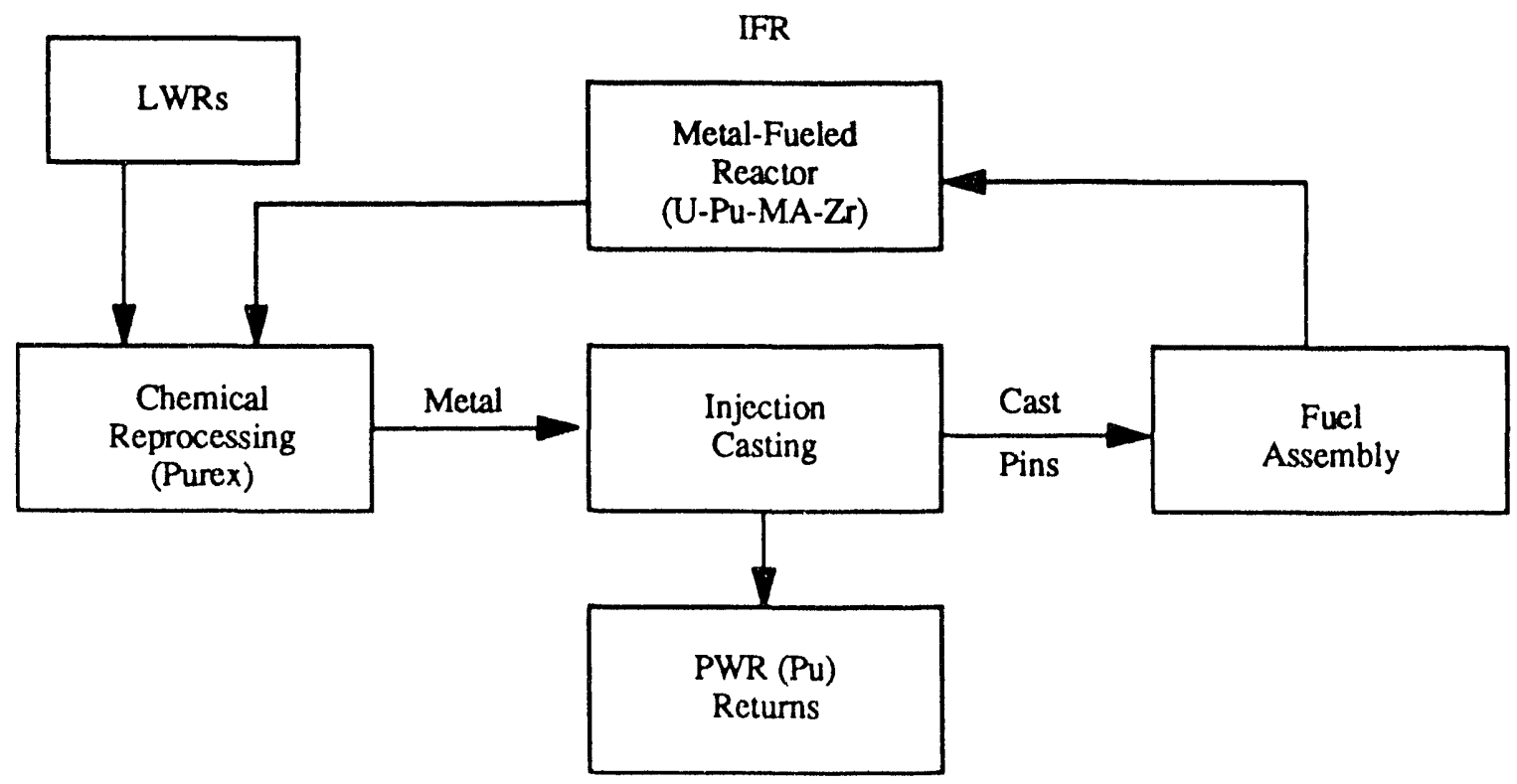

Figure B.1. SRS Fuel Cycle Using Injection Casting for IFR Fuel 


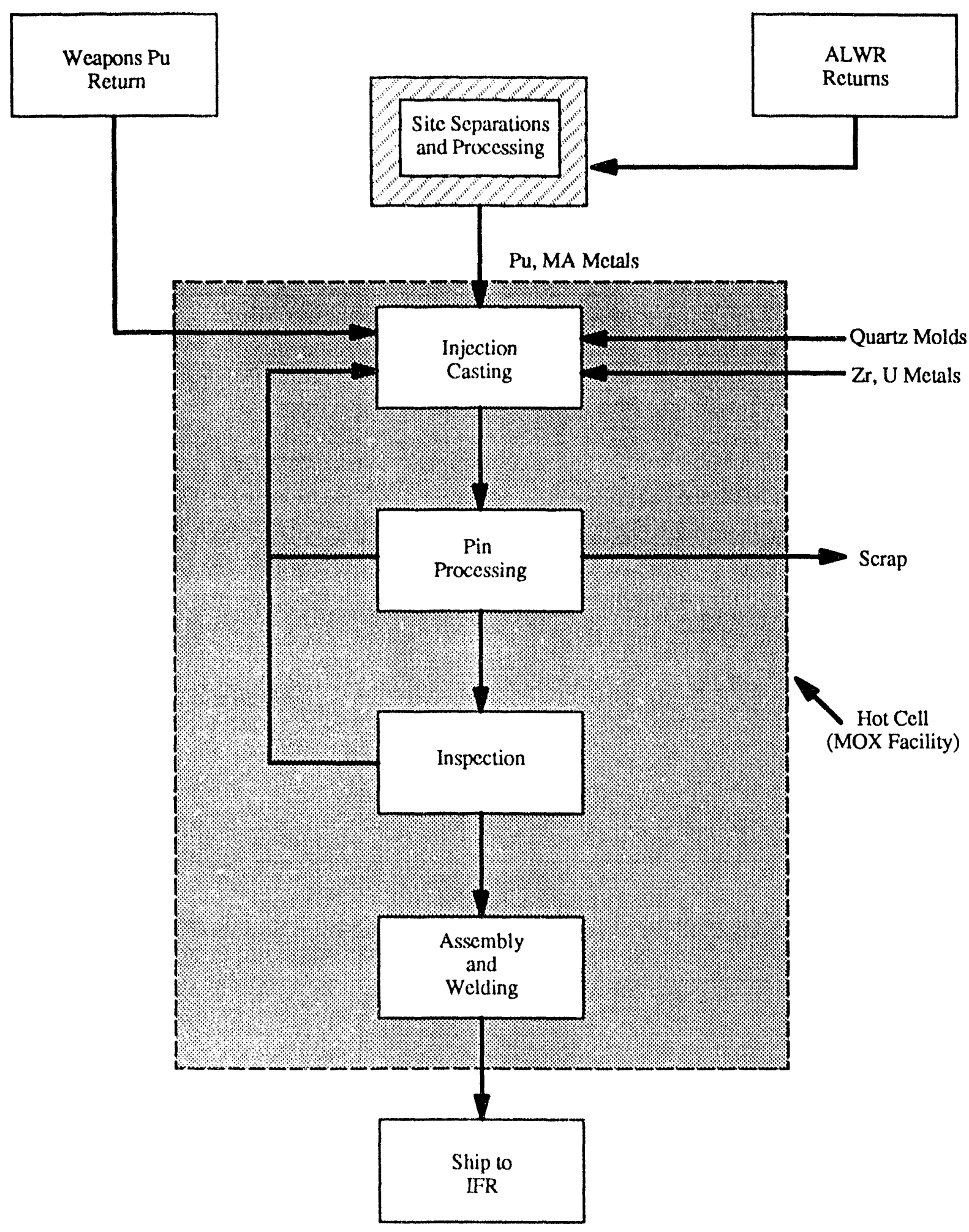

Figure B.2. Flowchan for IFR Fuel Fabrication 
a second cycle of solvent extraction in centrifugal contactors. The purified uranium solution would be precipitated with ammonia solution and the solids roasted to oxide for recycle to the ALWR fuel fabrication facility. The plutonium solution from the first cycle would be adjusted and purified by two additional cycles of solvent extraction in centrifugal contactors. The purified plutonium solution would be concentrated, precipitated with oxalic acid, and the oxalate would be roasted to the oxide. The oxide can be recycled to fuel fabrication for the ALWRs or reduced to metal with calcium using standard pyrometallurgical tech- nology. Plutonium metal would be sent to fuel fabrication for the IFR.

The aqueous waste solutions from the PUREX process and any other aqueous waste streams that contain actinides would be combined and evaporated before recovering transplutonium actinides, neptunium, and residual plutonium by the TRUEX solvent extraction process under development at Argonne National Laboratory. The TRUEX process recovers $>99.99 \%$ of all actinides leaving only fission products in the waste solution. The waste solution

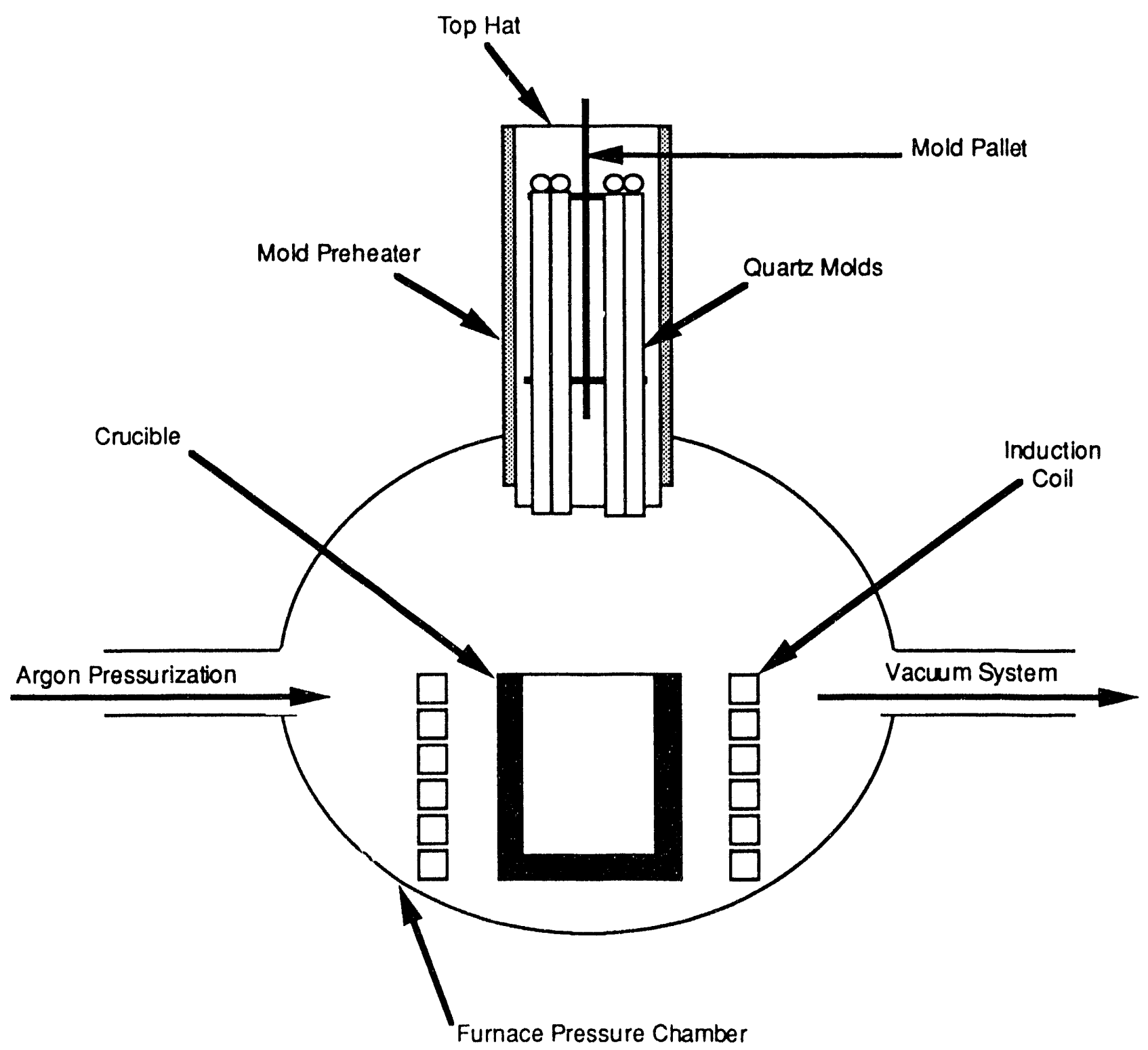

Figure B.3. Cross Section of the Alloy Preparation/Injection Casting Furnace 


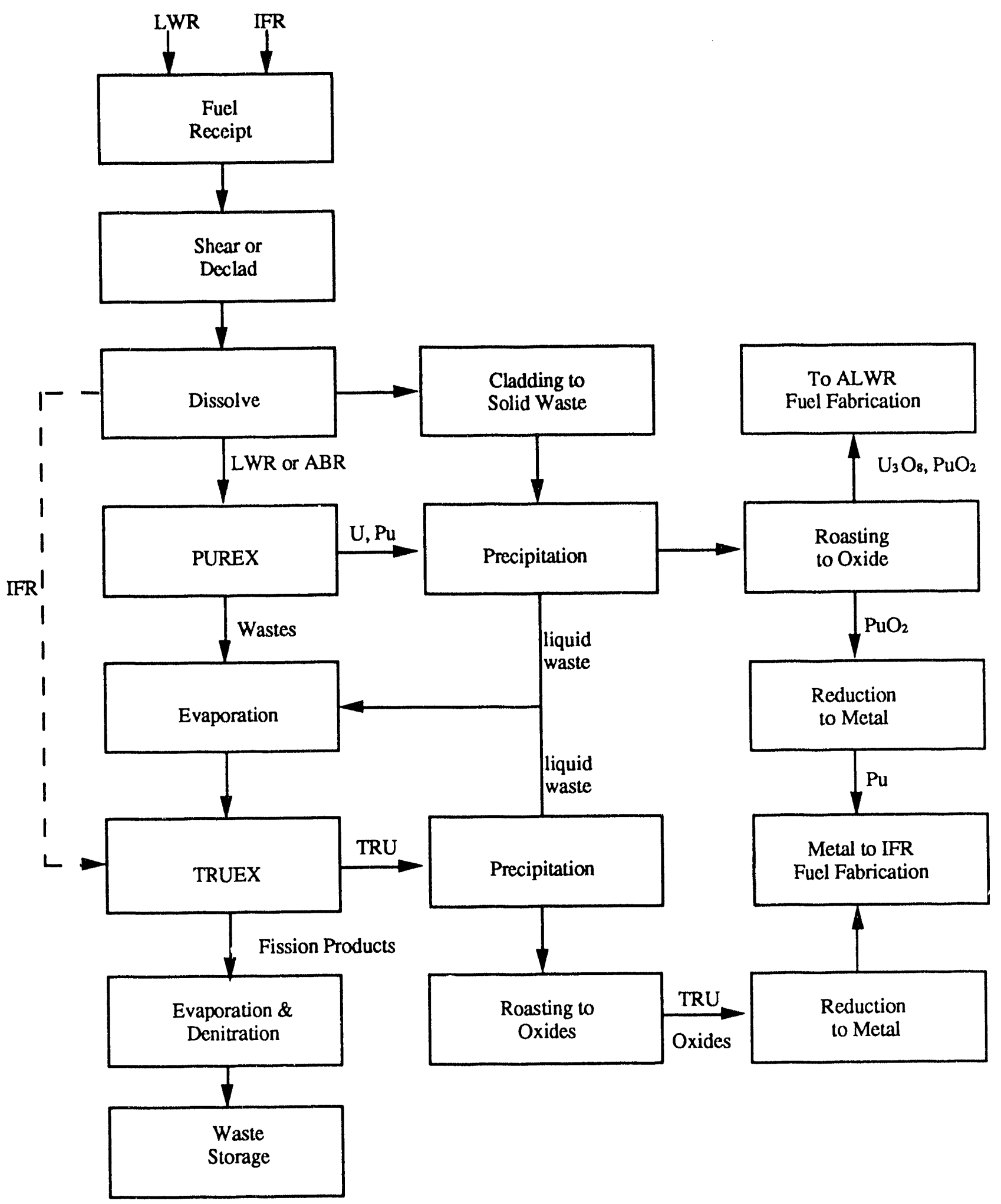

Figure B.4. Reprocessing Flow Diagram 
from the TRUEX process is evaporated further, denitrated, and transferred to waste storage tanks. The fission products would be eventually vitrified in a DWPF-like facility (if not in the DWPF itself). The combined actinides would be precipitated, roasted to oxide, reduced to metal, and transferred to fuel frhrication for the IFR.

Reprocessing the metal alloy IFR fuel requires the fuel cladding to be shredded and the alloy dissolved in nitric acid containing fluoride or some other catalyst to ensure safe dissolution. Once in nitric acid solution, IFR fuel can be processed through the last two cycles of plutonium solvent extraction or sent directly to the TRUEX cycle to recover plutonium along with the other actinides. The recovered actinides would be converted to metal as before for refabrication into IFR fuel. The short-lived fission and reaction products, again, would be sent to the waste tanks for eventual vitrification.

The reprocessing plant would be state-of-the-art with solvent extraction in remote canyon-like facilities and subsequent processing in shielded cells to minimize radiation exposure to the workers. Operations would also be automated as much as possible to minimize human error. The reprocessing plant would have state-of-the-art in-line and at-line instrumentation for process control.

If the above aqueous process were to be chosen within eight years to demonstrate partitioning with actinide burning, a large portion of the expense could be saved by using portions of the existing $\mathrm{H}$ or $\mathrm{F}$ Canyon facilities at SRS. After seven or eight years, these canyor facilities are expected to shut down and restart expense, would probably preclude their usefulness to the demonstration.

This proposed reprocessing flant is not sufficiently well developed to attempt an estimate of the costs.

\section{B.3 Actinide Burning in Integral Fast Reactor}

Actinide burning in a fast reactor requires some design changes from the standard LMR, which is designed to breed plutonium in blankct assemblies. In an actinide burner reactor, the blanket region is removed, resulting in a homogeneous core with a breeding ratio less than 1 . The reference US D.OE advanced liquid metal reactor concept utilizes the General Electric PRISM (Power Reactor, Innovative Small Module) design, in conjunction with the IFR pyroprocess being developed at Argonne National Laboratory. A PRISM plant consists of three $465 \mathrm{MWe}$ power blocks, each of which contains three modular reactors. If the blanket assemblies are removed from the
PRISM reactor modules and the LWR discharge fuel actinides are used as feed material, it would take approximately two power blocks ( $930 \mathrm{MWe}$ ) to consume the yearly actinide discharge from one $1000 \mathrm{MWe}$ LWR. This concept requires minimum modifications and analysis from the current advanced liquid metal reactor concept.

The minor actinides can be disposed of much more efficiently if the plutonium in the ALWR discharge is recycled to the ALWR feed stream, and only the minor actinides are sent to the IFR. Argonne National Laboratory has proposed conceptual designs that are fueled only by minor actinides. Since U-238 is fertile, its presence in reactor fuel leads to the production of plutonium and other actinides. Therefore, the fuel for minor actinide burner reactors contains no U-238. This type of core presents challenges in maintaining low sodium void worths and burnup reactivity swings, two very important safety considerations in fast reactor design. Purdue University has proposed using a two-region core; the inner region would be fueled by minor actinides while the outer would contain conventional fast reactor fuel assemblies (plutonium fueled). This configuration solves many of the safety problems associated with a minor actinide fueled core. However, the fuel and associated fuel cycle for such a reactor are purely conceptual at this stage, and would require a significant developmental effort before a serious evaluation could be made.

Construction of an actinide burner reactor would not need to begin until some time after startup of the ALWR(s). This is important because it provides additional development time for the advanced technologies required for the burner reactors. The actinides would be separated from the ALWR discharge fuel and stored until enough has accumulated for a startup actinide burner core or until burner construction is completed. The length of tim $:$ this will require is a function of the number and size of the ALWRs, the size of the actinide burner reactor, and whether the burner fuel is limited to minor actinides only.

The cost of an actinide burner reactor would be dependent on the size and type of reactor, fuel cycle choices, etc. General Electric estimates the cost of electricity from a PRISM plant (burning standard fast reactor plutonium fuel) would be approximately $38 \mathrm{mills} / \mathrm{kWh}$, slightly higher than that from an ALWR. General Electric also claims that costs for a dedicated burner using actinide fuel including plutonium would be only a modest increase over the standard design. Costs for a minor actinide burner (no plutonium in the fuel) cannot be estimated at this time, because so much research and development and design work remains to be performed. 


\section{B.4 Additional Reactors at SRS (with Reprocessing)}

Phase 3 of this strategy involves constructing and operating additional ALWRs, or other advanced reactor concepts beyond the initial plant, to eliminate excess plutonium in the U. S. weapons stockpile. Because spent MOX fuel reprocessing is expected in this phase, most of the recovered plutonium would be recycled back into these reactors. As envisioned, the group of advanced reactors would be located within a government-owned energy complex. Because this phase is almost identical to Strategy 2, Section 5.2 (and Section 4.1.2) should be referred to for additional details.

\section{B.5 High-Level Waste Management at SRS with Reprocessing and Actinide Burning}

\section{B.5.1 Waste From LWR Fuel}

Reprocessing MOX fuel as an alternative to direct disposal generates a liquid high-ievel waste (HLW) similar to but containing greater fission product concentration than the defense HLW historically generated in SRS operations. The SRS waste currently stored onsite in large steel tanks will be processed to a solid glass waste form in the Defense Waste Processing Facility (DWPF). Disposition of the HLW produced by onsite ALWR operation would depend on the timing of startup of reactor operation and the volume of waste generated. With one year cooling of fuel before processing and five-year cooling of liquid HLW before conversion to glass, most of the ALWR waste would be generated after the projected completion of processing for the existing waste inventory about the year 2010. The relatively small volumes of ALWR waste could, therefore, require providing new processing facilities, as appropriate, for the downsized operations supporting new waste generation. For purposes of this report, it is assumed that DWPF feed preparation facilities, including new liquid waste storage tankage, would be available for ALWR wastes in conjunction with refurbishing a chemical reprocessing canyon, but that the DWPF could be modified to accommodate solidification of the wastes, using the existing glass melting capability.

In a typical feed preparation nowsheet, neutralized waste from the chemical reprocessing would be centrifuged to separate sludge from soluble salt and the remaining solution would be processed to remove soluble fission products (Cs-137) by ion exchange. Both centrifuged sludge and a cesium-loaded waste fraction recovered by ion-exchange would be fed to the DWPF glass melter. The decontaminated salt solution, stored as necessary to allow residual radionuclide decay, would be processed to "saltstone" as in current operations. A flow diagram for this sequence is shown in Figure B.5. Alternative processing, based on acid waste handling with waste solutions fed directly to the melter, could also be utilized.

Reprocessing of ALWR fueis from a representative 3-reactor operation would generate an alkaline slurry of HLW. Assuming soliois content of $122 \mathrm{lbs}$ oxide/MTHM ${ }^{4}$, the wastes from 8.4 MTHM fuel could be immobilized at $28 \mathrm{wt}$ $\%$ within the $3650 \mathrm{lbs}$ glass contained in a DWPF canister, provided heat generation limits on the canister were not exceeded. After six years of aging, however, the wastes from 8.4 MTHM would generate about 15,000 watts decay heat, and, limiting canister heat generation to specifications about 1000 watus/canister, would require reducing waste concentration in the glass equivalent to about 0.5 MTHM/ canister. At this level, three-reactor ALWR operation (51 MT'AM/yr) would generate about 100 waste glass canisters per year. Continued operation of the DWPF, with modifications to accommolate feed streams from alternative salt processing operations, would be feasible at these canister production rates.

The glass waste canisters that are produced would be stored for an interim time in vault facilities analogous to the Glass Waste Storage Facility that is provided for existing wastes. Capacity for up to about 400$)$ canisters would be required assuming interim storage over the projected 40-year lifetime of the reactors.

Providing waste processing facilities in the chemical processing canyon to replace DWPF feed preparation in the tank farms would be undertaken as part of a general upgrade of the canyon facilities to support LWR fucl reprocessing. The cost of new waste handling facilities is estimated to be $\$ 100$ million. Incremental operating cost of the waste management facilities is projected at $\$ 30$ million per year.

Upgrading DWPF facilities, with input fecd matcrial streams from the canyon facilities would cost $\$ 100$ million in capital expenditures. Continued operation of the DWPF, costing currently about $\$ 150$ million/yr to support annual output of 400 canisters, is projected at $\$ 75$ million/year for the 100 canister output of the three L.WR operation at SRS. Incremental additions to the Glass Waste Storage Facility to accommodate a 40 -year reactor output of 4000 canisters would cost about $\$ 80$ million.

Fee payments to cover offsite transport and repository disposal of the glass waste canisters are projected at 


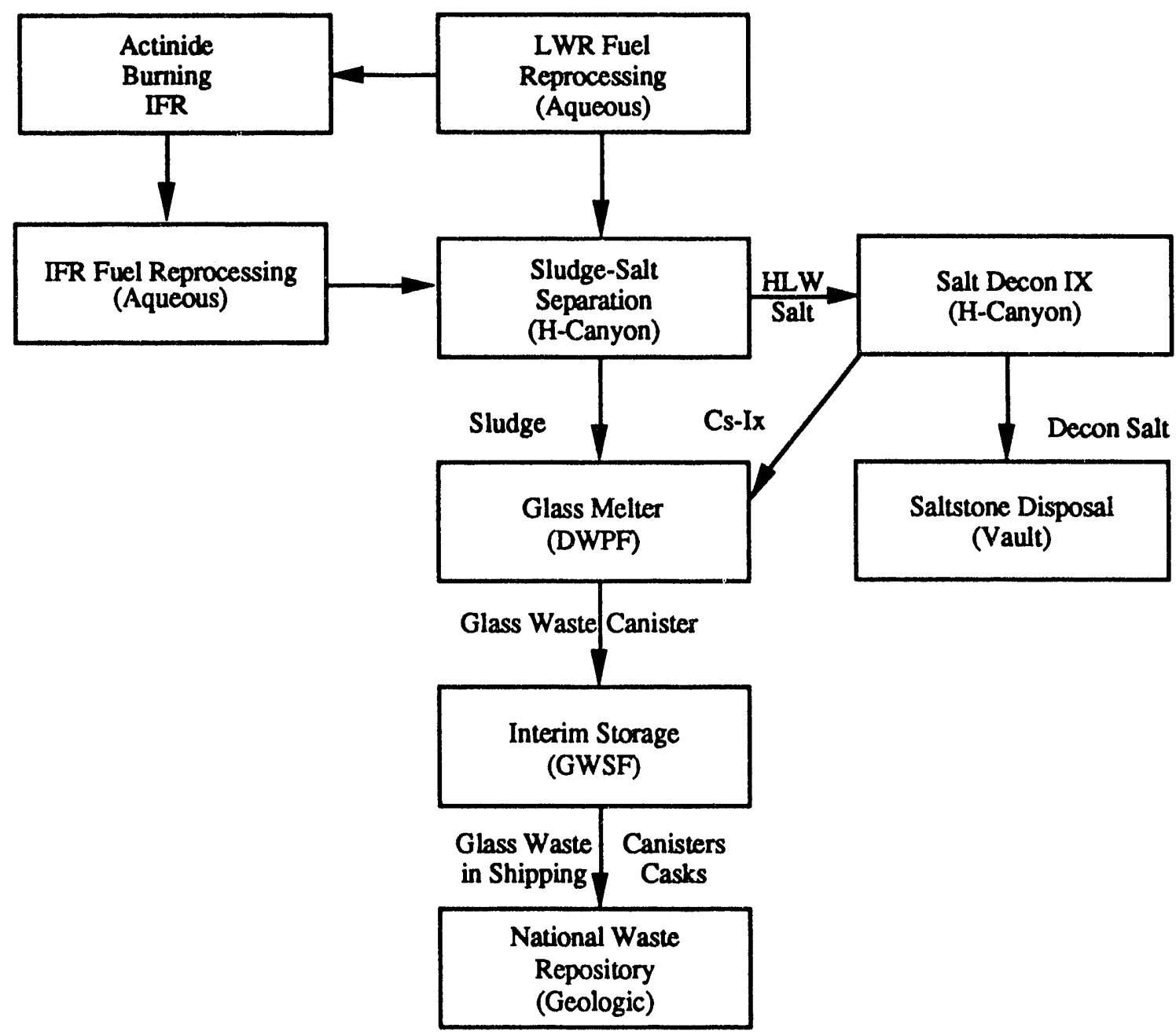

Figure B.5. Spent Fuel Reprocessing with Actinide Burning

$\$ 300,000$ per canister corresponding to unit costs currently assessed for glass waste canisters produced from existing chemical-processed waste, assuming a two-repository operation. The repository costs supporting three LWR operation at SRS is estimated to be $\$ 30$ million/yr, considerably greater than projected costs of $\$ 14$ million/yr for disposal of equivalent quantities of spent fuel without reprocessing, as calculated from the commercial spent fuel disposal fee. The difference is due to the restrictions on heat load allowed for canisters of the DWPF design. Canisters of special design (smaller diameter) to permit greater heat loads could be used to reduce the repository disposal costs for HLW produced by chemical processing of the LWR fuel.

\section{B.5.2 Wastes from Actinide Burning in Liquid Metal Reactors}

An IFR generating $4000 \mathrm{MWt}(1400 \mathrm{MWe})$ power should be capable of burning the approximately $30 \mathrm{~kg} / \mathrm{yr}$ output of minor actinides (MA) generated by a three-unit $600 \mathrm{MWe}$ ALWR operation. The reference IFR loaded with 15 MT/year of a metallic fuel with nominal composition (depleted uranium, $27 \%$, plutonium, $10 \%$ zirconium) would require replacement of $2-3 \%$ of the core actinides (1/3 MA) annually. 
High-level waste resulting from the IFR actinide burning operation would be produced during aqueous processing of the irradiated fuel, for conversion to glass waste as described in the preceding section. Since heat load limits determine the waste content of the LWR waste glass, incremental quantities of glass waste produced by the associated IFR operation would be proportional to the relative powers of IFR and LWR operation. For a $4000 \mathrm{MWt}$ IFR, an incremental 75 glass waste canisters would be produced annually.

Assuming processing through the same DWPF feed preparation and glass melting facilities provided for the LWR wastes, only small incremental capital charges of $\$ 60$ million (for additional interim storage capacity) and $\$ 25$ million per year operating costs are projected. Repository charges for the incremental 75 glass waste canisters produced would be about $\$ 22$ million/yr assessed at $\$ 300,000$ per canister for a two repository system.

\section{References}

1. "Trying Transmutation", Scientific American, p 36, May 1992.

2. Y.I. Chang and C.E. Till, "Advance Breeder Cycle Uses Metallic Fuel". Modern Power Systems, 11: 59, 61 and 63 April 1991.

3. Y.I. Chang and C.E. Till, "Economic Prospects of the Integral Fast Reactor (IFR) Fuel Cycle", presented at the International Conference on Fast Reactors and Related Fuel Cycles (FR'91), Kyoto, Japan, Vol. II, pp 18.6-1-18. 6-6. (October 28-November 1, 1991).

4. J.E.Hoisington. DWPF Capacity for Shear/Leach Waste. U.S. DOE Report, DPST-82-363, Savannah River Site, Aiken, SC 29898 (March 24, 1982). 


\section{Appendix C. Calculation of Co-Generation Electric Rate}

Based on a phone conservation with the South Carolina Public Service Commission ${ }^{1}$, the following table of electric rates, paid by South Carolina utilities to small co-generators, was developed.

Duke Power's peak rates are in effect 16 hours per day, Monday through Friday, all year long. There is no difference between summer and winter rates and the peak rate is adjusted by the capacity credit rate (i.e., adds on to peak rate). Therefore, the average electric rate can be computed by weight averaging the peak and off-peak rates as shown below:

$$
\begin{aligned}
\text { Average Rate } & =[80 \mathrm{hr} / \mathrm{wk}(3.13 \mathrm{c/kWh}+1.17 \mathrm{c/kWh} \\
& +88 \mathrm{hr} / \mathrm{wk}(2.32 ₫ / \mathrm{kWh})] / 168 \mathrm{hr} / \mathrm{wk} \\
& =3.26 \mathrm{kWh} \text { (yearly) }
\end{aligned}
$$

Carolina Power \& Light (CP\&L) summer rates are in effect from April through September, inclusive. The summer rate remains constant throughout, but the premium rate (capacity credit) varies. From June through September, the premiums $1.44 \mathrm{c} / \mathrm{kWh}$, but from October through May the premium is only $1.24 \mathrm{k} / \mathrm{kWh}$. Peak rates are in effect 12 hours per day, Monday through Friday. Using weight averaging, the average summer rate is:

Type of Rate

I. Energy Credit'

Duke Power

A. Surmmer

1. Peak

2. Off-Peak

3.13

2.32

B. Winter

1. Peak

2. Off-Peak

3.13

2.32

II. Capacity Credit

A. Summer

B. Winter
1.17

1.17

$$
\begin{aligned}
\text { Average Rate }= & \{60 \mathrm{hr} / \text { week }[4.12 \nsubseteq / \mathrm{kWh}+.33(1.24 \\
& ₫ / \mathrm{kWh})+.66(1.44 \mathrm{kWWh})] \\
+ & 108 \mathrm{hr} / \text { week }(2.96 \nsubseteq / \mathrm{kWh})\} / 168 \\
& \mathrm{hr} / \text { week } \\
= & 3.86 \mathrm{c} / \mathrm{kWh} \text { (summer only) }
\end{aligned}
$$

By performing a similar calculation, the average winter rate can be shown to be equal to $3.81 \mathrm{c/kWh}$. The yearly average is just the simple average of the summer and winter rates of $3.84 \$ / \mathrm{kWh}$.

South Carolina Electric \& Gas (SCE\&G) summer rates are in effect from June through September and the peak rate runs 12 hours per day, Monday through Friday. Winter rates are in effect from October through May and the peak rate is valid 12 hours per day, Monday through Friday. Using the same weight, averaging techniques from above, the average summer rate can be shown to be $2.71 \mathrm{c/kWh}$ and the average winter rate is $2.63 \mathrm{q} / \mathrm{kWh}$. Applying weight averaging to these rates yields a yearly average rate of $2.66 \mathrm{~d} / \mathrm{kWh}$.

The overall average of Duke Power, CP\&L, and SCE\&G is $3.25 \mathrm{k} / \mathrm{kWh}$.

\section{References}

1. Telephone Conversations with Randy Erskine of the South Carolina Public Service Commission on Electric Rates for Co-Generators, June 5, 1992, and July 9. 1992.

\section{Rate in $\mathbf{k} / \mathbf{k W h}$ CP\&L}

SCE\&G

$\begin{array}{ll}4.12 & 2.55 \\ 2.96 & 2.03\end{array}$

$\begin{array}{ll}4.12 & 2.26\end{array}$

$2.96 \quad 2.06$

1-Basic rate on-or off-peak

2-Premium rate added to peak only
1.44

1.24
1.39

1.39 

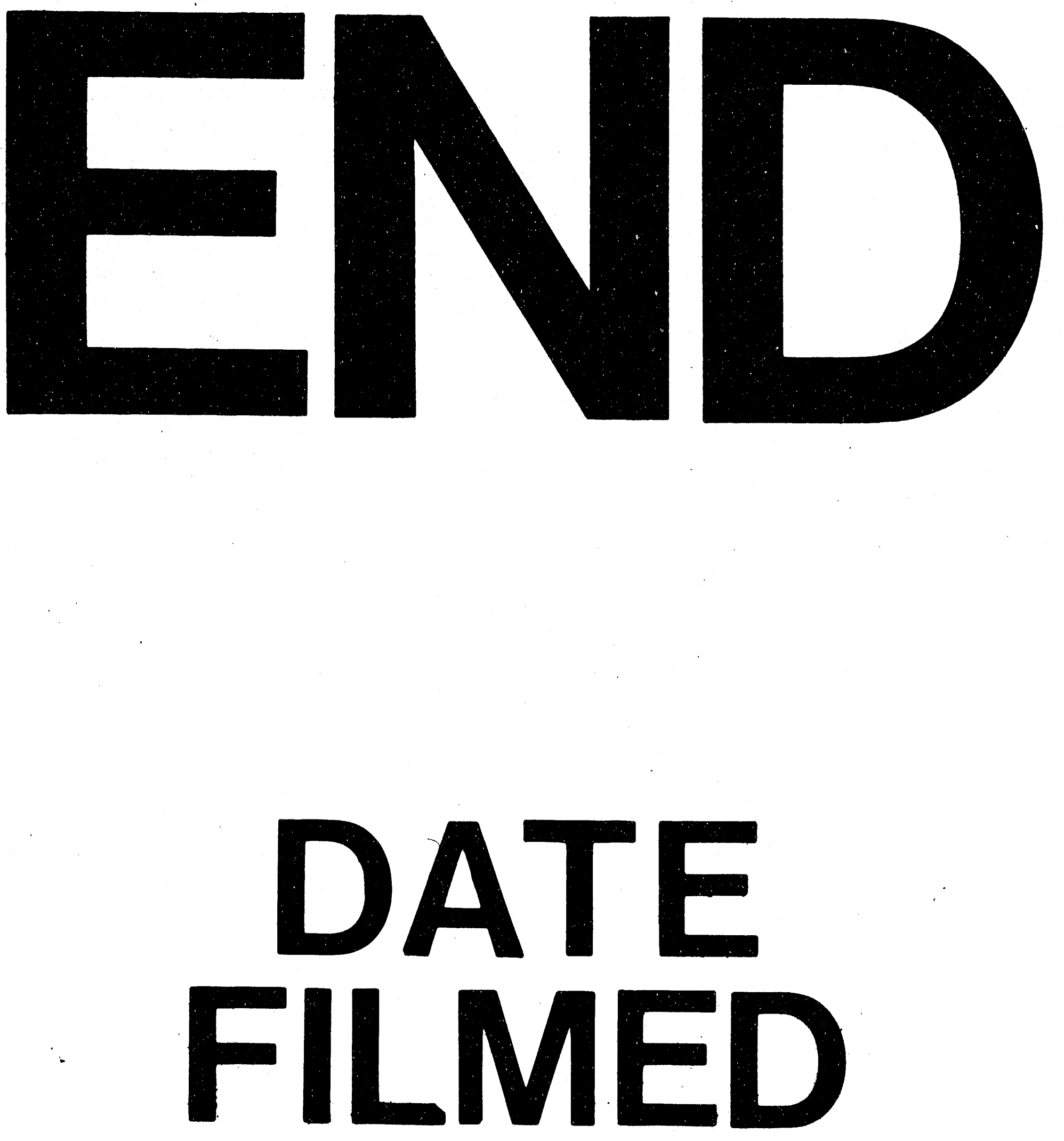

1

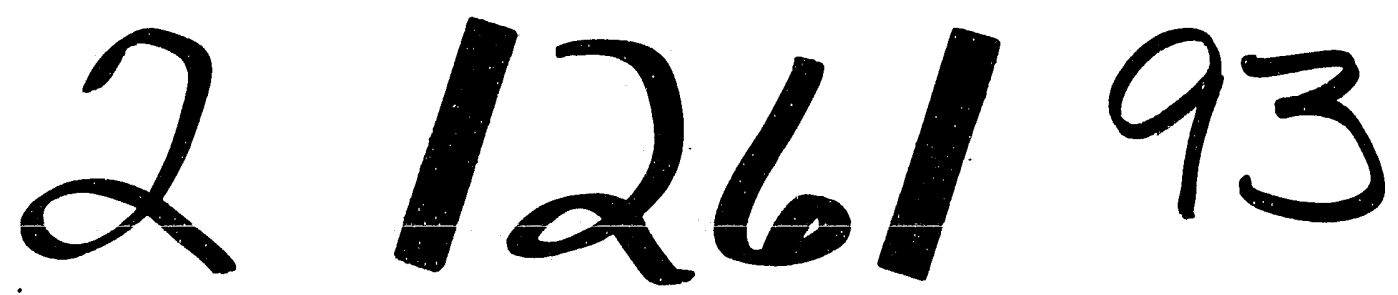


